\title{
Ostracoda from Johnston Atoll, Pacific Ocean, and Proposal of a New Tribe, Bruuniellini (Myodocopina: Cylindroleberididae) ${ }^{1}$
}

\author{
Louis S. Kornicker and Elizabeth Harrison-Nelson ${ }^{2}$
}

\begin{abstract}
Two new species of Ostracoda (Myodocopina), Parasterope pacifica Kornicker \& Harrison-Nelson and Bruuniella beta Kornicker \& HarrisonNelson, from Johnston Atoll are described and illustrated. The ontogeny of the latter species is also described. In addition, the name Bruuniella alpha Kornicker \& Harrison-Nelson is proposed for Bruuniella species A, previously described by Kornicker from the western Atlantic; a supplementary description of the species is provided. A new tribe, Bruuniellini, in the subfamily Cylindroleberidinae, family Cylindroleberididae, is proposed to include the genus Bruuniella, and keys are given to the two tribes in the subfamily and to the four known species of Bruuniella. The adult male of a species of the genus Bruuniella is described for the first time.
\end{abstract}

Johnston Atoll lies in the central North Pacific Ocean ca. 1,325 km WSW of Honolulu, in the vicinity of $16^{\circ} 45^{\prime} \mathrm{N}, 169^{\circ} 31^{\prime} \mathrm{W}$ (Coles et al. 2001:1). It consists of a shallow coral reef platform approximately $14 \mathrm{~km}$ long and $6 \mathrm{~km}$ wide. It includes two natural small islands (Johnston Island, which is the larger, and Sand Island) and two small islands built by dredging and filling. The U.S. Fish and Wildlife Service is responsible for stewardship of the atoll. Staff of the Bishop Museum (Honolulu, Hawaici) in June 2000 conducted a study of the marine biotic community; the myodocopid ostracodes described herein were collected in that study. For a comprehensive description of the atoll and its history see Coles et al. (2001). The atoll has been the scene of much construction, mainly to facilitate its use by the U.S. Navy and Air Force. Of interest is that during 1958 and 1962, three thermonuclear devices

\footnotetext{
${ }^{1}$ Manuscript accepted 2 June 2004.

2 Department of Zoology, National Museum of Natural History, Smithsonian Institution, Washington, D.C. 20013-7012 (e-mail: kornicker.louis@nmnh.si.edu.).
}

Pacific Science (2005), vol. 59, no. 3:323-362

(C) 2005 by University of Hawai'i Press

All rights reserved were detonated over the atoll at altitudes of 33, 76, and $200 \mathrm{~km}$. Station locations are shown in Figure 1, and station data are presented in the Appendix. Myodocopid Ostracoda have not been described previously from the atoll. The appendage designated fifth limb herein is called second maxilla by some authors (Cohen et al. 1998).

\section{MATERIALS AND METHODS}

Sampling methods used at the stations are described in Coles et al. (2001:4), but the method of collecting the ostracodes is not specifically given. Podocopa in the collection are more diverse than Myodocopa and were sent to Rosalie Maddocks, University of Houston, Houston, Texas.

\section{RESULTS}

\section{Disposition of Specimens}

The holotypes and most paratypes have been deposited in the National Museum of Natural History, Smithsonian Institution, Washington, D.C., and have been assigned UsNM catalog numbers. Several paratypes of each species have been deposited in the Bishop Museum, Honolulu, Hawai' $i$, and have been assigned врвм-S numbers. 


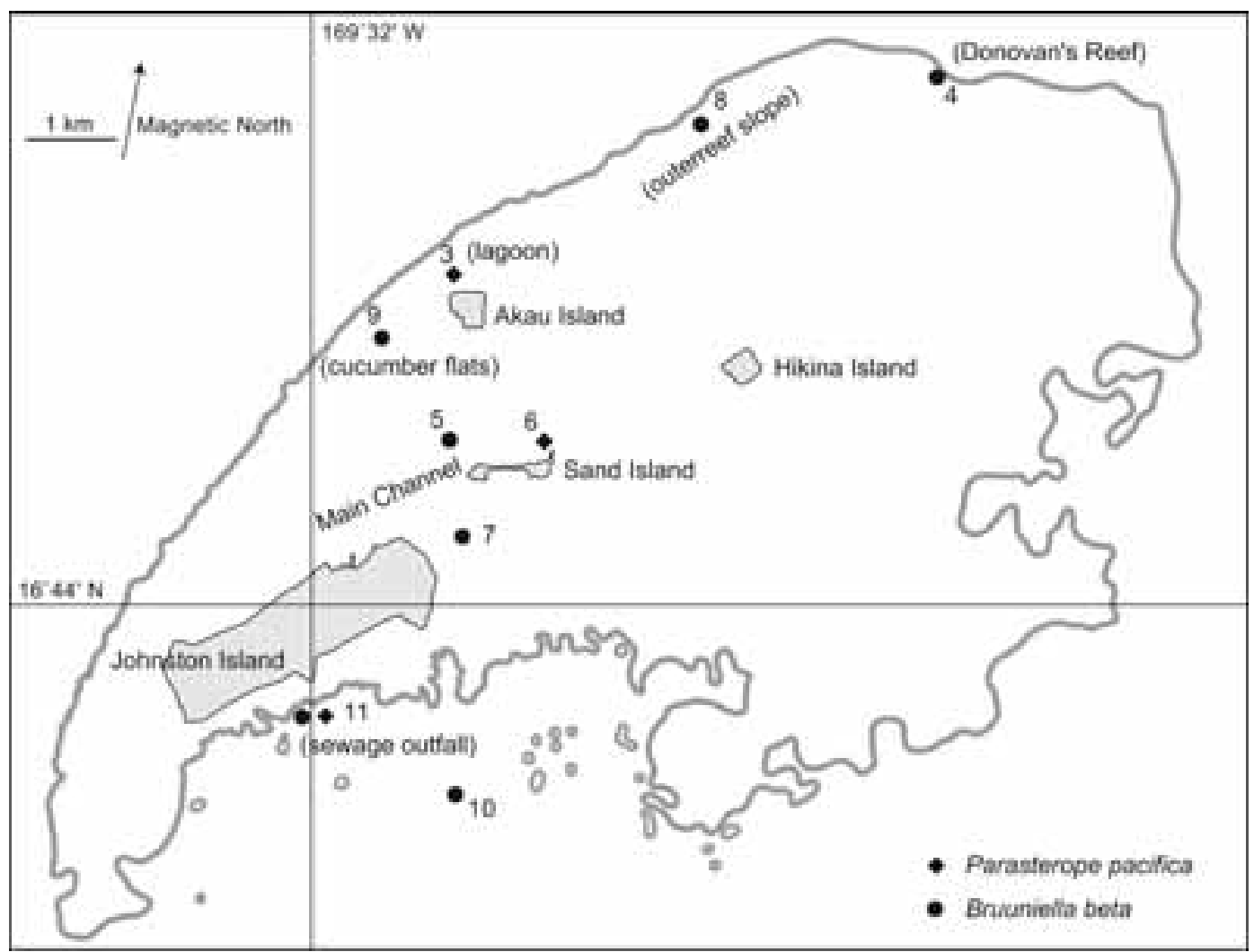

FIgURE 1. Map of Johnston Atoll showing location of stations and species distribution (data in Appendix). (Base map adapted from Coles et al. [2001: fig. 1].)

Order Myodocopida Sars, 1866

Suborder Myodocopina Sars, 1866

Superfamily CyLindroleberidoideA

Müller, 1906

Family Cylindroleberididae

Müller, 1906

COMPOSITION AND Distribution: The Cylindroleberididae include three subfamilies: Cylindroleberidinae Müller, 1906; Cyclasteropinae Poulsen, 1965; and Asteropteroninae Kornicker, 1981a. Members of the family are widespread in marine environments at intertidal to abyssal depths. Only members of the Cylindroleberidinae were collected in the vicinity of Johnston Atoll.

\section{Subfamily Cylindroleberidinae Müller, 1906}

composition and Distribution: The Cylindroleberidinae include two tribes: $\mathrm{Cy}-$ lindroleberidini Müller, 1906, and Bruuniellini Kornicker \& Harrison-Nelson, n. tribe. Members of the subfamily are widespread in marine environments at intertidal to abyssal depths.

Tribe Cylindroleberidini Müller, 1906, n. status

COMPOSITION AND Distribution: The Cylindroleberidini include 17 genera and are 
widespread in marine environments at intertidal to abyssal depths.

\section{Genus Parasterope Kornicker, 1975}

Type SPecies: Asterope muelleri Skogsberg, 1920:483; subsequent designation by Kornicker (1975:401).

Distribution: Widespread between latitudes of about $55^{\circ} \mathrm{N}$ and $65^{\circ} \mathrm{S}$. Depth range, intertidal to 4,303 $\mathrm{m}$ (Kornicker and Caraion 1974:7).

Parasterope pacifica Kornicker \& HarrisonNelson, n. sp.

Figures 2-5, 22

HOLOTYPE: USNM 1023194, ovigerous female on two slides and in alcohol. $3)$.

TYPE LOCALITY: Johnston Atoll (Station

paratypes: Johnston Atoll: Station 3, USNM 1023195, 6 juveniles; Station 6, UsNM 1023196, 5 juveniles; Station 11, врвм-S 12246, 4 juveniles.

Distribution: Johnston Atoll.

DESCRIPTION OF ADULT FEMALE (Figures $2-5)$ : Carapace in lateral view wider in posterior part (Figure $2 A$ ).

Infold: Rostral infold with about 35 bristles (Figure 2D); anterodorsal infold with 15 bristles forming row. Anteroventral infold with about 23 bristles (Figure 2E); ventral infold with about 26 bristles. Posterior infold with broad band along inner margin with about 30 flaplike bristles and about 13 short slender bristles (not more than 2 between pairs of flaplike bristles) (Figure $2 F, G$ ). Ventral part of posterior infold with 10 or 11 long bristles between broad band and posteroventral valve edge (Figure $2 F$ ). Anteroventral, ventral, and posterior parts of valve with narrow band along inner edge with row of closely spaced minute pores or processes (Figure 2E,G); narrow band lies farther from valve edge on right valve than on left valve.

Central adductor muscle attachments (Figure $2 B, C$ ): Each valve with 12 oval attachments.

Carapace size (length, height in $\mathrm{mm}$ ): USNM 1023194: 1.16, 0.74 .
First antenna (Figure $3 A-D$ ): 1st article: hairs forming lateral row near dorsal margin and longer hairs distally; distal dorsal corner with transparent spinous flap (Figure $3 C$ ). 2nd article: dorsal margin with few hairs and terminal cluster of spines (Figure 3A,D); lateral side with short distal bristle; dorsal margin with long distal spinous bristle. Oblique suture separating 3rd and 4th articles well defined. 3rd article: short ventral margin with small bristle; long dorsal margin with 6 bristles ( 2 with bases lateral, 4 with bases along dorsal edge; both lateral bristles and proximal 3 edge-bristles with long proximal and short distal spines; 4th edge-bristle with short spines). 4th and 5th articles separated by concave suture more strongly developed on medial side. 4th article: long ventral margin with distal spines and 2 terminal bristles; short dorsal margin with long bristle with short spines. 5th article: dorsal margin without spines; sensory bristle with long stem and 6 long filaments, each with minute terminal tubercle. 6th article with fairly long medial bristle. 7th article: a-bristle clawlike with proximal minute teeth along dorsal margin; b-bristle with 3 marginal filaments; c-bristle long with 4 marginal filaments. 8th article: d-bristle absent or represented by minute peg (Figure $3 B$ ); ebristle longer than a-bristle, bare with blunt tip; f-bristle bent dorsally, with 4 marginal filaments; g-bristle with 4 filaments. Total bristles 20 .

Second antenna (Figures $3 E-H, 4 A$ ): Protopod with small distal medial bristle and few long distal spines on dorsal margin (Figures $3 E, 4 A$ ). Endopod with 3 articles (separating sutures indistinct), with long terminal filamentlike bristle (Figures $3 E, 4 A$ ). Exopod with 9 articles: articles 1 to 3 with small spines forming medial row near distal margin (spines on article 1 farther from distal end than spines on articles 2 and 3); articles 2 to 8 with smaller spines forming row along inner margin of terminal edge; articles 4 to 8 with stout lateral basal spines (Figure $3 F, G$ ); 9th article with stout lateral spine. Bristle of 2 nd article reaching past 9th article, with short ventral spines; bristle of article 2 with proximal ventral spines and distal natatory 


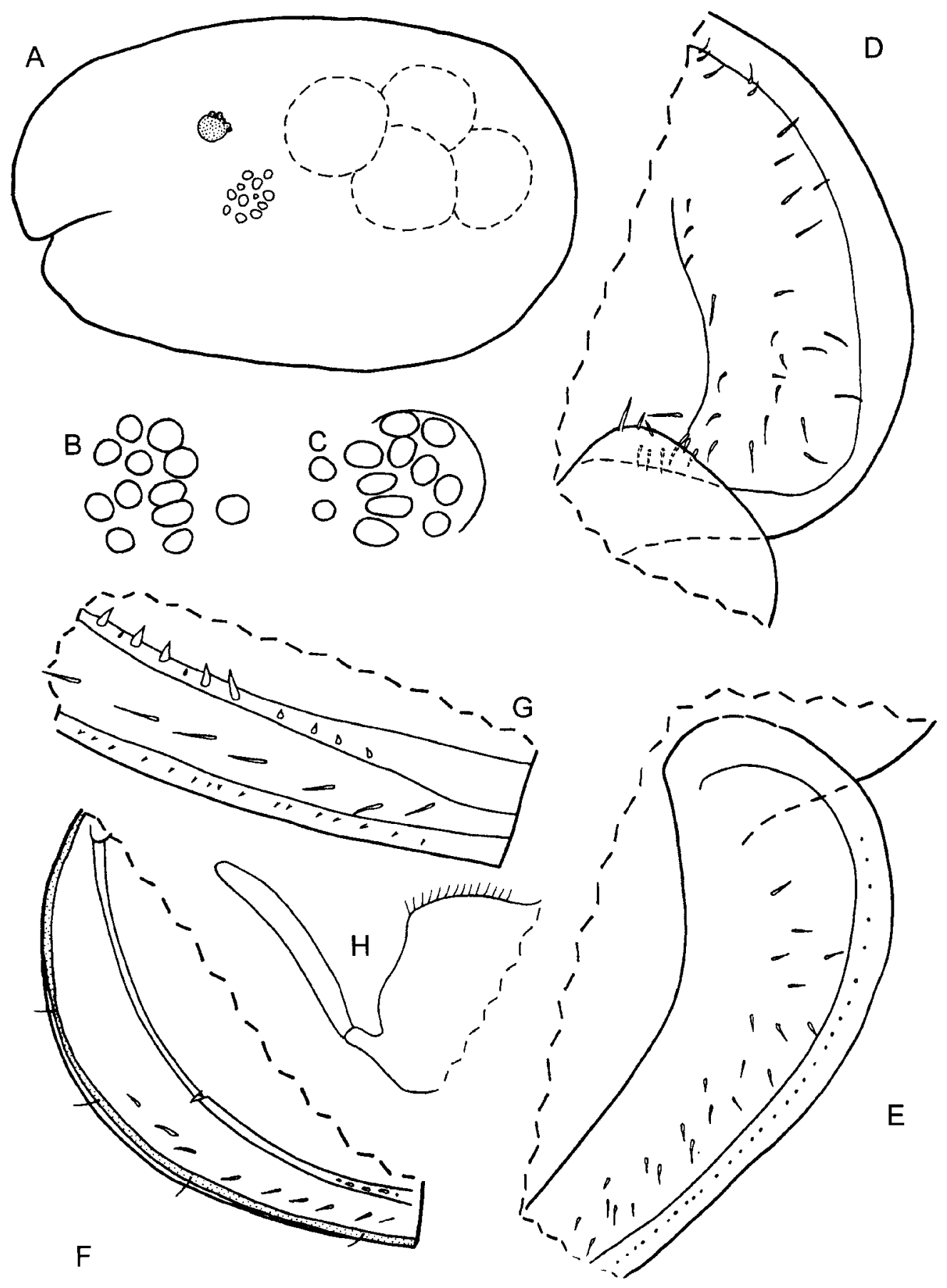

Figure 2. Parasterope pacifica, n. sp., holotype, usnm 1023194, adult female: $A$, complete specimen, length $1.16 \mathrm{~mm}$; $B, C$, central adductor muscle attachments of right and left valves, respectively, inside view; $D, E$, anterodorsal and anteroventral views of left valve, respectively, inside view; $F$, posterior view of left valve, inside view; $G$, posteroventral edge of left valve, inside view; $H$, medial eye and Bellonci Organ, lateral view. 


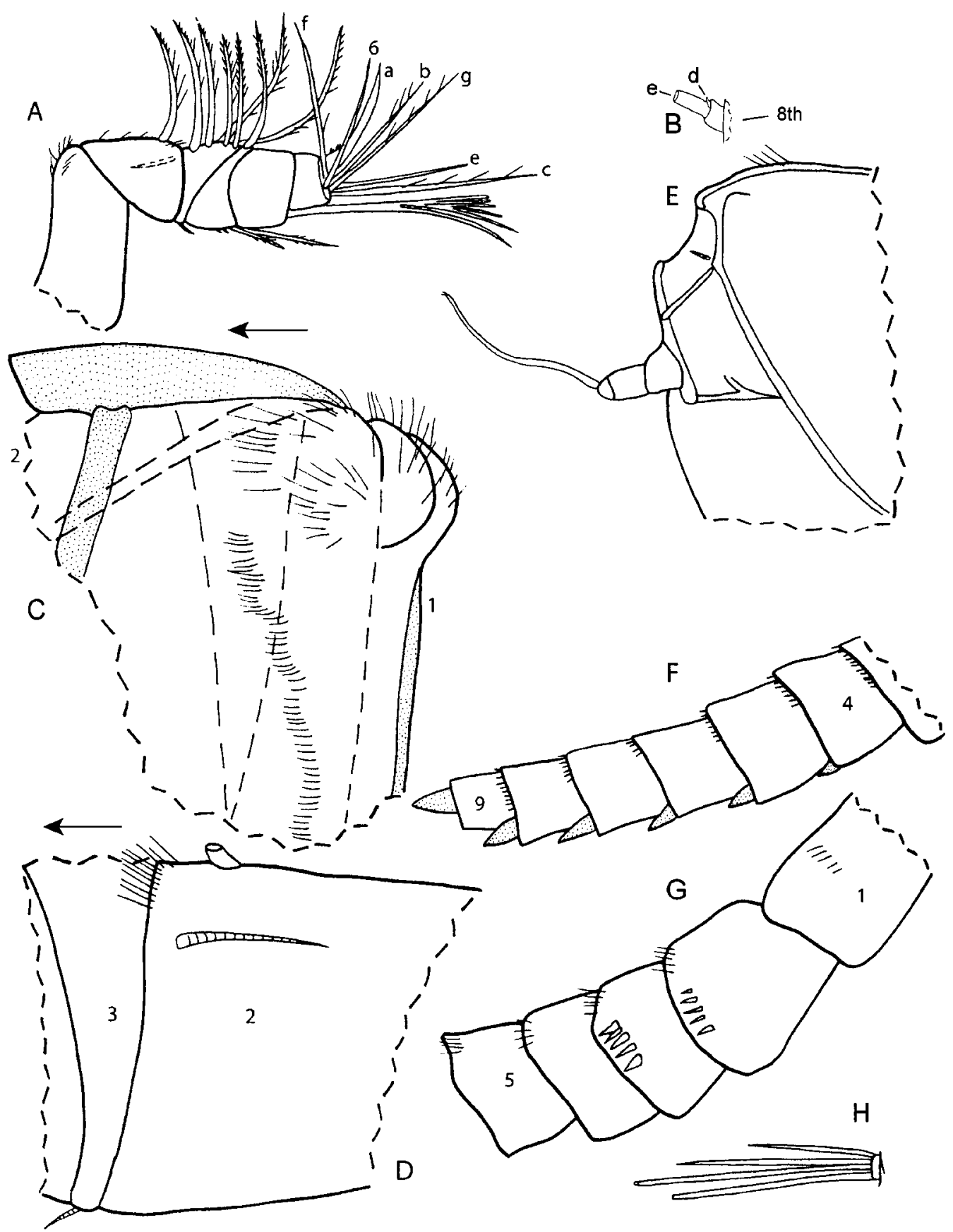

Figure 3. Parasterope pacifica, n. sp., holotype, usNm 1023194, adult female: $A-D$ : left 1st antenna: $A$, complete limb, medial view; $B$, d- and e-bristles of 8 th article, lateral view; $C$, distal dorsal corner of article 1, lateral view; $D$, articles 2 and 3, lateral view. $E-H$ : 2 nd antenna: $E$, protopod and endopod of right limb, medial view; $F$, part of exopod of right limb, lateral view; $G$, part of exopod of left limb, medial view; $H$, bristles of article 9 of exopod of right limb, lateral view. 
hairs; bristles of articles 3 to 8 with only natatory hairs; 9th segment with 4 bristles (2 dorsal bristles short, either bare or with indistinct minute spines; middle bristle shorter than ventral bristle, both with natatory hairs). Pivot sclerite slightly concave (Figure $4 A$ ). Total bristles 14 .

Mandible (Figure 4B,C): Dorsal branch of coxa endite broken off both limbs of holotype (projecting into mouth, obscured); ventral branch of left limb partly obscured but with many spines (Figure 4C). Basis endite with 4 spinous end bristles, 2 triaenid bristles with 3 or 4 pairs of spines plus terminal pair, and glandular peg; medial dwarf bristle proximal to peg obscured and appeared to be broken on illustrated limb. Ventral margin of basis with triaenid bristle (with 3 pairs of spines plus terminal pair) just proximal to Ushaped process; dorsal margin of basis with 2 long spinous terminal bristles. Exopod almost as long as dorsal margin of 1st endopod article, with 2 short terminal bristles and distal dorsal hairs. Endopod: 1st article with 3 long ventral bristles ( 1 with short spines, 2 with short proximal and long distal spines). 2nd article: dorsal margin with 1 or 2 short slender proximal bristles followed by a-, b-, c-, and d-bristles (c-bristle much stouter than others), lateral side of dorsal margin with 1 long bristle between b- and c-bristles, and 1 long bristle between c- and d-bristles; medial side near dorsal margin with 8 short cleaning bristles $(3$ forming oblique row between band c-bristles and 5 forming oblique row between c- and d-bristles), and 1 long bristle adjacent to d-bristle; ventral margin with 3 long terminal bristles with short marginal spines (medial of these shorter and stouter than others). 3rd endopod article with stout terminal dorsal claw with minute ventral teeth, 3 long terminal bristles with short proximal ventral spines; 1 short medial terminal spinous bristle near ventral margin and 1 long medial terminal bristle (with short ventral spines) just ventral to base of dorsal claw. Total bristles 39 .

Maxilla (Figure $5 A$ ): Endite I with 4 bristles (3 long, 1 short), endite II with 3 long bristles. Epipod with tapered tip reaching about midlength of dorsal margin of basis.
Basis with proximal short lateral bristle near dorsal margin, distal short dorsal bristle, proximal backward-pointing short ventral bristle, and long spinous terminal ventral bristle. Ventral margin of comb with about 88 bristles. Endopod: 1st article with small dorsal alpha-bristle and long terminal betabristle (tip of bristle obscured); 2nd article with long terminal bristle. Total bristles approximately 99 .

Fifth limb (Figure 4D): Epipod with about 65 bristles. Comb with 1 long spinous exopod bristle, 2 short slender bristles just ventral to base of exopod bristle, 4 short bristles (ventral to base of exopod bristle) with bases almost on ventral edge of comb, and 1 similar proximal bristle. Dorsal edge of comb with distal hairs. Ventral margin of comb with about 35 bristles. Oblique section anterior to epipod with about 27 bristles. Total bristles approximately 139.

Sixth limb (Figure 5B): Anterior proximal corner with minute medial bristle. Anterior margin with 2 endite bristles. Ventral margin with 2 spinous anterior bristles separated by space from 15 to 18 spinous bristles (posterior 7 or 8 bristles with long spines; shorter bristles anterior and with long proximal and short distal spines). Anterior, ventral, and posterior margins, and medial surface spinous. Lateral flap spinous but without bristles. Total bristles 20-23.

Seventh limb (Figure 5C,D): Limbs long, each with about 67 rings, 6 proximal bristles ( 3 on each side) and 6 terminal bristles ( 3 on each side); each bristle with 3 or 4 distal bells. Terminus with opposing combs, each with 9 spinous teeth. Total bristles 6 (24 including terminal combs).

Furca (Figure 5E): Each lamella with 6 claws (with posterior teeth and anterior spines) followed by 2 or 3 ringed spinous bristles. Total claws and bristles 8-9.

Bellonci Organ (Figure 2H): Elongate with rounded tip.

Eyes: Medial eye colorless with dorsal hairs (Figure $2 \mathrm{H}$ ). Lateral eye well developed with many ommatidia and black pigment (Figure $2 A$ ).

Gills (Figure 5E): With 7 well-developed gills on each side. 


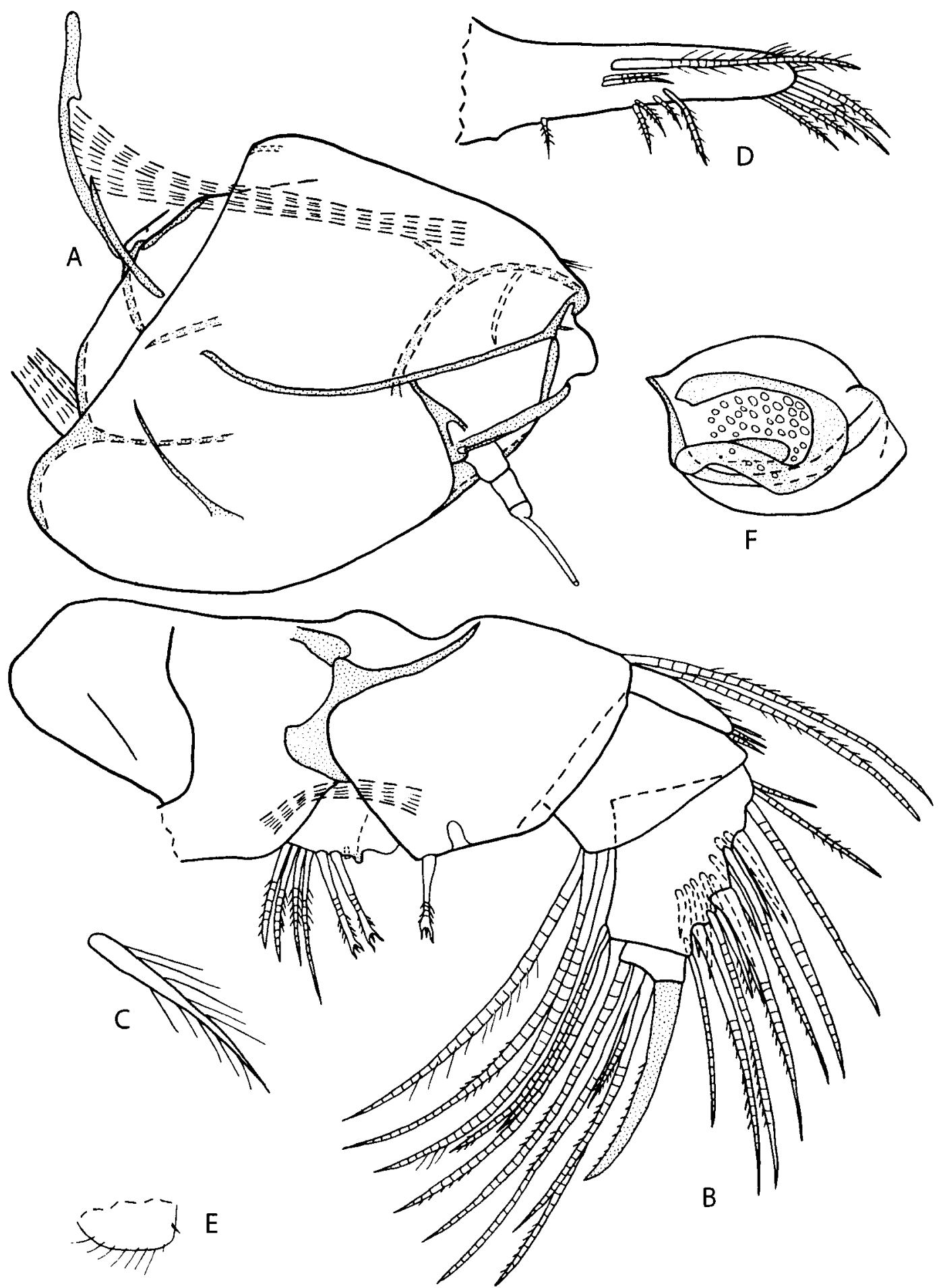

Figure 4. Parasterope pacifica, n. sp., holotype, USNM 1023194, adult female: $A$, protopod and exopod of left 2nd antenna, medial view; $B$, right mandible, lateral view; $C$, ventral branch of coxa endite of left mandible, lateral view; $D$, comb of right 5 th limb, lateral view; $E$, upper lip, anterior to right, lateral view; $F$, genital organ. 
Lips (Figure 4E): Upper lip rounded, with ventral hairs and anterior spine.

Posterior of body (Figure $5 F$ ): With long hairs dorsal to furca and at posterodorsal corner and, also, on both sides of posterior part of body. 4 spinous crescents form row just within posterior margin of each side of body just dorsal to posterior end of girdle.

Y-Sclerite (Figure 5E): Elongate with pointed anterior tip.

Genitalia (Figure 4F): Oval with minute globules.

Eggs (Figure 2A): UsNM 1023194, with 6 eggs of similar size; diameter of 1 egg $0.21 \mathrm{~mm}$.

Protistan: Ventral edge of right valve near posteroventral corner with stemmed eggshaped protistan.

comparisons: The new species, $P$. pacifica, differs from P. obesa Poulsen, 1965, reported from Misaki, Japan, in having no bristles ( $P$. obesa has 3$)$ on the lateral flap of the 6th limb, in having 2 slender bristles instead of 1 just ventral to the base of the exopodial bristle on the comb of the 5th limb, and in having 4 spinous crescents near the posterior margin of the body dorsal to the posterior end of the girdle. Parasterope pacifica differs from P. jenseni Poulsen, 1965, from the Sagami Sea, Japan, in not having spines along the ventral edge of the protopod of the 2 nd antenna, and in having a lateral bristle on the 2nd article of the 1st antenna, and spinous crescents on the posterior of the body. Parasterope pacifica differs from $P$. skogsbergi Poulsen, 1965, from the vicinity of Thailand, in having no bristles on the lateral flap of the 6th limb, and in having spinous crescents on the posterior of the body. Parasterope pacifica differs from P. nana Poulsen, 1965, from the vicinity of Thailand, and from $P$. bulingsi Baker, 1978, from the vicinity of San Marco Point, California, in the shell not being elliptical in lateral view, and in the 6th limb having many ventral bristles.

Parasterope pacifica is close to $P$. pectinata Poulsen, 1965, from the vicinity of Three King's Island, New Zealand. Both have spinous crescents on the posterodorsal part of the body and a row of long stout distal hairs on the dorsal margin of the 2 nd article of the 1st antenna. The basis of the maxilla of $P$. pa- cifica bears a distal dorsal bristle absent on $P$. pectinata. Parasterope quadrata (Brady, 1898), from Lyttelton Harbor, New Zealand, differs from $P$. pacifica in having a bristle at midlength of the dorsal margin of the basis of the mandible. Parasterope quadrata was also reported from Japan by Kajiyama (1912:618), but the description given is insufficient for positive verification, and the probability of it being $P$. pacifica is unlikely because of the long distance between the places where the two species were collected.

Parasterope pacifica is also close to P. muelleri (Skogsberg, 1920), which is widespread in the Atlantic and also bears spinous crescents on the posterodorsal part of the body. The dorsal margin of the 5th article of the 1st antenna of specimens from Bermuda, Florida, and the Bahamas, identified as $P$. muelleri by Kornicker and Iliffe (2000:84: fig. $52 a-c)$, bears a row of minute distal spines that are absent on $P$. pacifica.

Hartmann (1984:121) described Parasterope lagunicola Hartmann, 1984, from Rangiroa Atoll in the Tuamotu Islands. The length of the female of that species is given as $0.90-1.03 \mathrm{~mm}$, smaller than $P$. pacifica (length $1.16 \mathrm{~mm}$ ). The illustration (fig. 24) of the 6th limb presented by Hartmann shows no endite bristles on the anterior margin, compared with 2 on $P$. pacifica. The illustration (fig. 22) of the mandible presented by Hartmann shows an exopod longer than the dorsal margin of the 1st endopod article, compared with an exopod shorter than the dorsal margin of the 1st endopod article of the mandible of $P$. pacifica (Figure 4B).

\section{Tribe Bruuniellini Kornicker \&} Harrison-Nelson, n. tribe

Type genus: Bruuniella Poulsen, 1965:323. composition and Distribution: The Bruuniellini include the genus Bruuniella. Members of the genus have been collected in the western Atlantic Ocean off North America and Belize, in Bermuda, in the Gulf of Thailand, and in the vicinity of Johnston Island, Pacific Ocean, all at shallow depths.

DIAGNosis: First antenna: articles 3 to 5 of adult female fused; dorsal margin of in- 

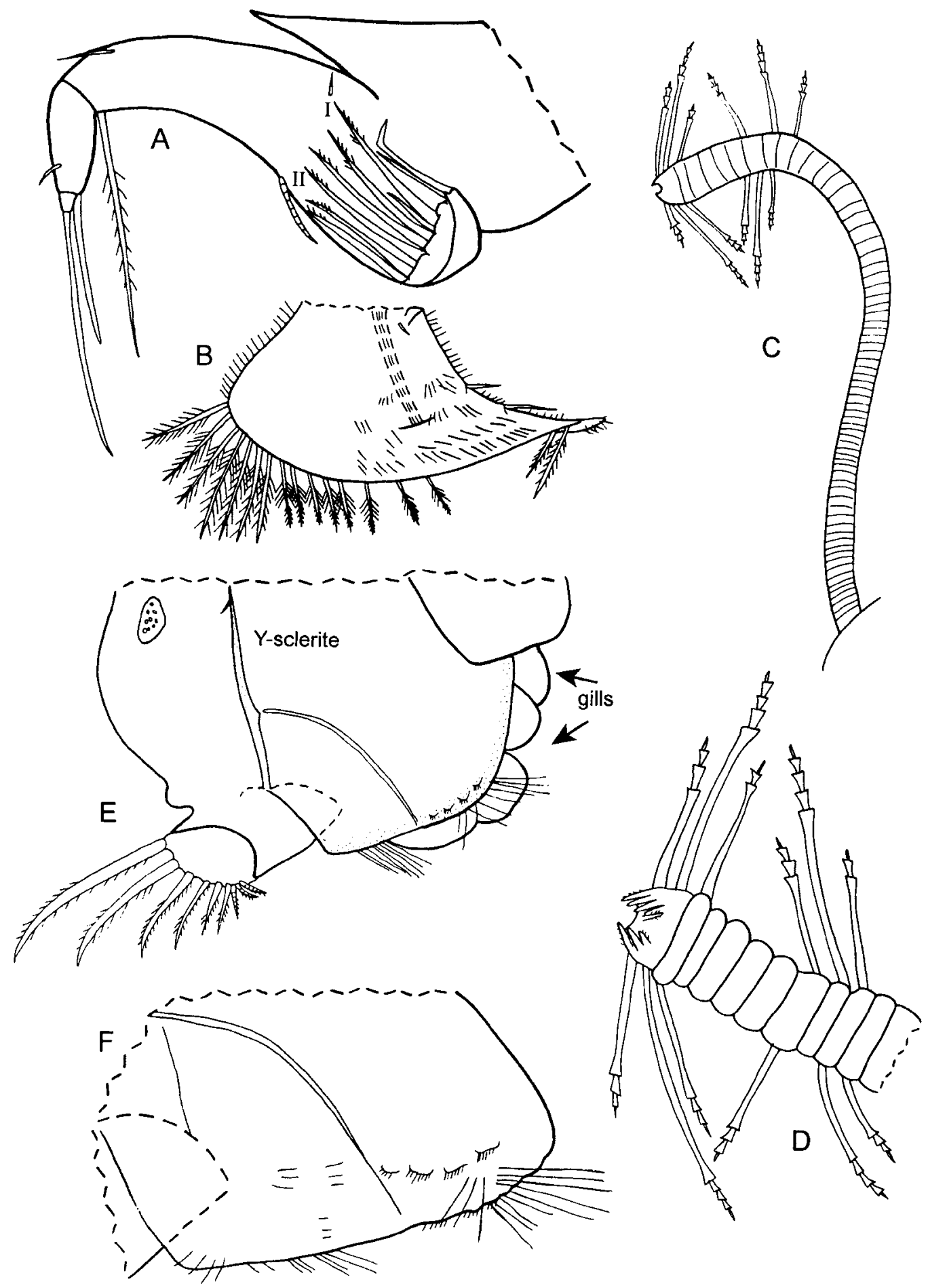

Figure 5. Parasterope pacifica, n. sp., holotype, usNM 1023194, adult female: $A$, left maxilla, lateral view; $B$, left 6th limb, medial view; $C, D, 7$ th limb; $E$, posterior of body from left side (genital organ with small circles; only tips of gills shown); $F$, posterodorsal corner of body from left side. 
ferred 3rd article with bristles with stout bases; articles 3 and 4 of adult male fused, and sensory bristle with base wedged between articles 2 and inferred fused articles 3 and 4. Mandible: articles 2 and 3 of endopod of adult female fused and short. Maxilla: except for B. breviata Poulsen, articles 1 and 2 of endopod fused. Anterior end of Y-sclerite in posterior part of body with looplike structure. Gills absent. Sutures separating articles 3, 4, and 5 of the 1st antenna in some species of Cylindroleberidini are indistinct, and some fusion occurs but not to the degree present in the Bruuniellini. Proximal displacement of sensory bristle of male 1st antenna unique for members of the Cylindroleberididae. Monoasterope bex Kornicker, 1991:125, bears a maxilla somewhat similar to those of some species of Bruuniella (not B. breviata Poul- sen), and it bears only rudimentary gills; its mandible is unlike that of species of Bruuniella in being similar to that of members of the Cylindroleberidini.

DISCUSSION OF NEOTENY OF 6TH LIMB: The 6th limbs of the first, free-living instar of known species of the Cylindroleberidinae are without bristles, which are added in the second instar. The 6 th limbs of known adults and late instars of B. alpha, n. sp.; B. beta, n. sp.; and B. bazeli Kornicker are without bristles, suggesting neoteny. Bristles are present on the 6th limb of B. breviata. Endite bristles are absent on 6th limbs of known adults and late instars of all four species of Bruuniella but are present on late instars and adults of other Cylindroleberidinae, which also suggests neoteny.

KEY TO SPECIES OF Bruuniella

1. Sixth limb with about 18 ventral bristles.......................... breviata Poulsen Sixth $\operatorname{limb}$ without numerous ventral bristles ............................. 2

2. Basis endite of mandible with 1 stout spinous bristle.......... beta, n. sp. (adult female) Basis endite of mandible with 2 stout spinous bristles $\ldots \ldots \ldots \ldots \ldots \ldots \ldots \ldots \ldots \ldots \ldots$

3. Basis endite of mandible with 2 slender bare bristles ............. alpha, n. sp. (A-1 male) Basis endite of mandible with 3 slender bare bristles .............. hazeli (adult female)

Genus Bruuniella Poulsen, 1965

TYPE SPECIES: Bruuniella breviata Poulsen, 1965:323, by monotypy.

COMPOSITION AND Distribution: The genus includes four species: $B$. breviata Poulsen, 1965, from the Gulf of Thailand; $B$. bazeli Kornicker, 1986, from the western Atlantic, off Massachusetts; $B$. alpha Kornicker \& Harrison-Nelson, renamed herein, from Bermuda and Belize (Cohen 1989:326, table 3 ); and B. beta Kornicker \& Harrison-Nelson, n. sp., herein, from Johnston Island, Pacific Ocean. All known specimens are from shallow depths. Morphologically the specimens from the West Atlantic, Bermuda, and Johnston Atoll are closer to each other (because of the absence of numerous bristles on the ventral margin of the 6th limb) than to the specimens from the vicinity of Thailand, which have numerous bristles on the 6th limb.
DisCUSSION OF RELATIVE ABUNDANCE: Poulsen (1965:323) proposed the genus Bruuniella for a new species, B. breviata Poulsen, 1965 , for a female and juvenile female collected in 1900 at Koh Chang, southeastern coast of Thailand, from corals at $2 \mathrm{~m}$ depth. A second species referred to Bruuniella species A (B. alpha herein) was described from an A-1 male collected in 1976 from Smith's Sound, Governor's Island, Bermuda, depth about $2 \mathrm{ft}$ [ca. $0.6 \mathrm{~m}$ ], by Kornicker (1981b:12, 1986:85). The Bermuda species was also reported from Belize by Cohen (1989:326, table 3). A third species, Bruuniella bazeli Kornicker, 1986, was described by Kornicker (1986:85) from Vineyard Haven Harbor, Martha's Vineyard, Massachusetts. Because only a single specimen of the latter species was available, L.S.K. recollected at the type locality in about 1984 but was unsuccessful in finding additional specimens. 
Because of the sparsity of specimens in previous collections of Bruuniella, it was indeed a welcomed surprise to have so many specimens in the collection from Johnston Atoll, which provided the opportunity to describe the first adult male as well as many instars. lini.

Diagnosis: Same as for tribe Bruuniel-

Bruuniella breviata Poulsen, 1965

Figure $10 G$

Bruuniella breviata Poulsen, 1965:323, figs. 107, 108.-Kornicker, 1986:85 (key to species).

Lectotype: Female with embryos, length $0.91 \mathrm{~mm}$, described and illustrated by Poulsen (1965:324-327, figs. 107, 108a-e); designated herein. In collection of the Zoological Museum of the University of Copenhagen.

TYPE LOCAlity: Koh Chang, southeastern coast of Thailand, coral, $2 \mathrm{~m}$ (Poulsen 1965:323, 327). Collected 1 March 1900. According to Poulsen (1965:5), "A list of Stations from Dr. Th. Mortensen's Expeditions 1900-30 is published as manuscript by Zoological Museum, Copenhagen." Because the two specimens were collected in 1900, they were probably collected during the 1900 expedition.

paralectotype: Juvenile female (A-2 instar), length $0.67 \mathrm{~mm}$, described and illustrated by Poulsen (1965:328, fig. 108f-g); designated herein. In collection of the Zoological Museum of the University of Copenhagen. (Identification of juvenile as A-2 instar is based on morphology of A-2 instar of $B$. beta described herein.)

material examined: None.

Distribution: Known only from type locality.

SUPPLEMENTARY DESCRIPTION: The original description of the species by Poulsen (1965:324) is comprehensive. Noted here are characteristics of the mandible and 6th limb of particular importance in distinguishing the species from the three other species referred to the genus.

First antenna: Total bristles on adult female 20, on A-2 female 16 (Poulsen 1965:324, 325, fig. 107b,c; 327, fig. 108f; 328).

Second antenna: Total bristles on adult and A-2 female 12 (Poulsen 1965:324, 325, fig. 107e; 327, fig. 108g; 328).

Mandible: Basis endite of adult female with 3 spinous bristles and 5 more slender bare bristles (2 long, 3 short) (Poulsen 1965:325, fig. 107g) (Figure 10G). Basis endite of A-2 female with 2 spinous bristles and 3 more slender bare bristles (Poulsen 1965:327, fig. 108b). Exopod with 1 terminal bristle (Poulsen 1965:325, fig. 107 $g, g^{\prime}$ ). Total bristles on adult female 27, on A-2 female 24 (Poulsen 1965:324, 325, fig. 107f- $b$; 327, fig. 108h; 328).

Maxilla: Poulsen (1965:326) did not illustrate the maxilla but described it as being essentially the same as those of other members of the type for the subfamily, and his description of the limb is supportive.

Sixth limb: Total ventral bristles on adult female 17 (Poulsen 1965:326, 327, fig. 108b).

Seventh limb: Total bristles on adult female 6, on A-2 female 4 (Poulsen 1965:327, fig. 108c).

Furca: Total claws and bristles on each lamella of adult female 8, of A-2 female 5 (Poulsen 1965:327, fig. 108d; 328).

\section{Bruuniella hazeli Kornicker, 1986}

Figure $10 H$

Bruuniella hazeli Kornicker, 1986:85, figs. 35, 36.

HOLOTYPE: USNM 152849, ovigerous female on 3 slides and in alcohol, unique specimen.

TYPE locality: Station 9, Vineyard Haven Harbor, Martha's Vineyard, Massachusetts.

MATERIAL eXAmined: Holotype slides. Distribution: Known only from type locality.

SUPPLEMENTARY DESCRIPTION AND DISCUSSION OF ADULT FEMALE HOLOTYPE (Figure 10H): First antenna: Sensory bristle of the 1st antenna of the holotype bears 2 short proximal filaments and 4 long distal filaments. Because the two previously reported species 
of the genus were reported to have 6 long filaments on the sensory bristle, the presence of the 2 short bristles on B. hazeli was considered by Kornicker (1986:85, key; 89) to be a distinguishing character. The 2 proximal filaments on the sensory bristle of the new species $B$. beta described herein vary in length and, therefore, the short filaments on the unique specimen of $B$. hazeli are probably not an important distinguishing character. Additional collections of the species are required to ascertain whether or not the lengths of the 2 filaments vary as they do in B. beta. Total bristles 20 .

Second antenna: Total bristles 12 .

Mandible: Kornicker (1986: 86; 88, fig. $36 a$ ) described and illustrated 5 or 6 minute bristles proximal to the coxa endite. On reexamination of the mandible it could not be ascertained if vague structures proximal to the coxa endite are actually bristles; therefore, it is prudent to discount the presence of bristles. Basis endite with 2 stout spinous bristles and 3 slender bare bristles (1 long, 2 short) (Figure 10H). Exopod with 2 terminal bristles. Total bristles 25.

Maxilla: Ventral margin of basis with 53 spoon-tipped bristles and 1 bristle with bent tip. Total bristles 62 or 63 . Differs from that of $B$. breviata in fusion of basis and endopod articles. tles.

Sixth limb: Ventral margin without bris-

Seventh limb: Total bristles 6 .

Lateral eye: With 20 ommatidia and dark pigment.

Y-Sclerite: With looped anterior end. COMPARISONs: Bruuniella bazeli differs from $B$. breviata in not having bristles on the ventral margin of the 6th limb and in having a maxilla with fused basis and endopod articles.

Bruuniella alpha Kornicker \& HarrisonNelson, n. sp.

Figure 10I

Bruuniella species A: Kornicker, 1981b:12, figs. 9, 10.-1986:85, key.

Holotype: USNM 158119, A-1 male on slide and in alcohol.
TyPe Locality: Smith's Sound, Governor's Island, Bermuda, associated with rocks, about 2 feet $[0.6 \mathrm{~m}]$ deep (Kornicker $1981 b: 12)$.

MATERIAL EXAMINED: Holotype.

Distribution: Known only from type locality.

SUPPLEMENTARY DESCRIPTION AND DISCUSSION OF HOLOTYPE (Figure 10I): The unique specimen was described by Kornicker $(1981 b: 12)$. The supplementary description below is limited to the total number of bristles and claws on each appendage. In addition, errors in the original descriptions of the maxilla and 6th limb are discussed and corrected.

First antenna: Total bristles 18.

Second antenna: Total bristles 15 .

Mandible: Basis endite with 4 bristles (2 stout, 2 slender) (Figure 10I). Total bristles 23.

Maxilla: Kornicker (1981b:14) described the basis of the maxilla as having a minute ventral bristle near midlength and illustrated a left maxilla showing the bristle (Kornicker $1981 b: 13$, fig. $10 g$ ). Reexamination of that maxilla revealed that the object identified as a bristle may be a foreign object or organism that resembles a bristle but is without the distinct walls generally characteristic of a bristle. The right maxilla is without a bristle or anything resembling a bristle in that location. It is tentatively concluded that the middle of the ventral margin of the basis of the specimen is without a bristle. Comblike ventral bristles (53) on basis plus proximal bristle with bent tip. Endite I with 2 bristles; endite II with 3 bristles. Fused endopod articles each with terminal bristle. Total bristles 60 .

Fifth limb: Epipod with about 50 bristles. Ventral margin of comb with about 27 bristles. Broad surface of comb with about 8 bristles. Very approximate total number of bristles 85 .

Sixth limb: Kornicker (1981b:14) described the right limb as having a single bristle at anterior end; the bristle is absent on the left limb. Reexamination of the right limb revealed that the identified bristle is probably clumped spines that resemble a bristle. It is without the striations mistakenly shown 
on the bristle in the illustration (Kornicker 1981b: fig. 10j). Total bristles 0 .

Seventh limb: Total bristles 4 .

Furca: Total claws on each lamella 5 .

Lateral eye: With 18 ommatidia and black pigment.

comparisons: The new species, $B$. alpha, differs from $B$. breviata in not having ventral bristles on the 6th limb; in having a mandible with 2 rather than 1 terminal bristles on the exopod and fewer than 5 bristles on the basis endite; in having a maxilla with fused basis and endopod articles; and in having a furca without a bristle following the claws on each lamella. Bruuniella alpha is very close to $B . b a-$ zeli, and they could be conspecific. Comparison is made more difficult because the former is known only from an A-1 male, and the latter from an adult female. The species are distinguished herein on the difference in the number of slender bristles on the basis endite of the mandible: $B$. alpha has 2 bristles compared with 3 on $B$. bazeli. The small difference in number of bristles is interpreted to be important because the number of bristles on the basis endite of the A-1 male and adult females of $B$. beta, described herein, are similar and show little variability. On the other hand, the number of slender bristles on the basis endite of the A-2 instar and adult female of $B$. breviata increases from 3 to 5 . Study of additional specimens is needed to determine the intraspecific variability of the endite bristles of B. alpha and B. hazeli to determine whether or not the two species should be synonomized.
Bruuniella beta Kornicker \& Harrison- Nelson, n. sp.
Figures 6-9, 10A-F, $7,11-23$

HOLOTYPE: USNM 1023197, ovigerous female on slide and in alcohol. 5).

TYPE LOCAlity: Johnston Atoll (Station

PARATYPES: USNM 1023198-1023202, врвм-S 12247-12253: Station 4, 3 specimens; Station 5, 25 specimens; Station 7, 4 specimens; Station 8, 3 specimens; Station 9, 1 specimen; Station 10, 11 specimens; Station 11, 6 specimens.
Distribution: Johnston Atoll.

DESCRIPTION OF ADULT FEMALE (Figures $6-9,10 A-F, \mathcal{F}, 22-23)$ : Each valve elongate in lateral view and with deep incisure (Figures $6 A, 8 A, 10 A, B, E)$. Dorsal margin convex; ventral margin tending to be linear to slightly convex and with slight concavity anterior to midlength on some specimens.

Infold: Broad infold along anterior, ventral, and posterior margins of valve (Figure $10 E$ ). Bristles present on rostral infold, anteroventral infold, and ventral infold. Stouter hyaline flaplike bristles present along inner edge of posterior infold (Figures $6 C, 8 C$ ); 2 processes present near midwidth of posterior infold; about 12 bristles present on posterior infold just within valve outer edge (Figure $6 C$ ). (Foreign growth on the 2 females examined obscured bristles of rostrum.)

Central adductor muscle attachments (Figures $6 A, B, 8 B, 10 A, E)$ : Consisting of 11-13 oval attachments.

Carapace size (length, height in $\mathrm{mm}$ ): USNM 1023203: 0.89, 0.53; USNM 1023197: $0.82,0.47$; USNM 1023209: 0.80, 0.50; USNM 1023198: 0.84, 0.59; USNM 1023208: 0.83, 0.44 (dorsal margin slopes downward posteriorly; furca not present on body).

First antenna (Figures 6D,E, 10C,D): 1st article bare. 2nd article with spinous dorsal bristle and without spines. 3rd to 5 th articles mostly fused; 3rd article fused to 4th; ventral margin of inferred 3rd article with few long hairs; dorsal margin of 3 rd article with 4 stout clawlike bristles with enlarged bases lateral to 3 slender spinous bristles and with 1 proximal spinous bristle. Inferred 4th article with 1 long dorsal bristle with short spines and 2 spinous ventral bristles; dorsal margin with numerous minute spines. 5th article essentially fused to 4th article but separated by fine suture on lateral side only (suture not present on some specimens); sensory bristle with 6 filaments (proximal 4 marginal [proximal 2 bristles more slender than others], distal 2 terminal); proximal 1 or 2 filaments short on one or both limbs of some specimens; dorsal margin and lateral surface near dorsal margin of article with numerous minute spines. 6th article long with short terminal medial bristle and minute spines along dorsal margin and 


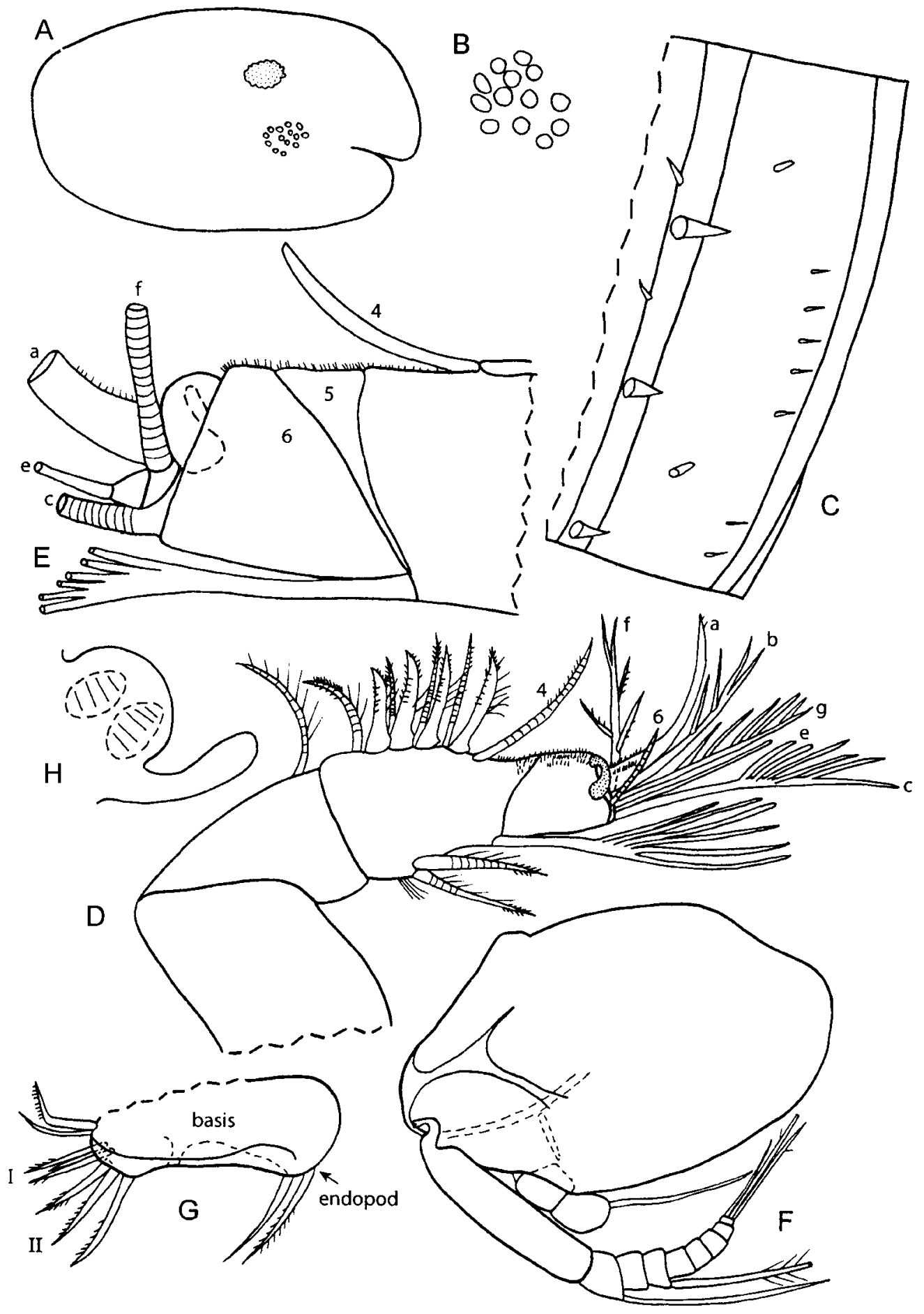

Figure 6. Brunniella beta, n. sp., holotype, usnm 1023197, adult female: $A$, complete specimen, length $0.82 \mathrm{~mm} ; B$, central adductor muscle attachments of right valve, outside view; $C$, section of posterior of right valve, inside view; $D$, left 1st antenna, medial view; $E$, distal left 1st antenna, lateral view; $F$, left 2 nd antenna, lateral view; $G$, right maxilla, lateral view; $H$, medial eye and Bellonci Organ from right side. 


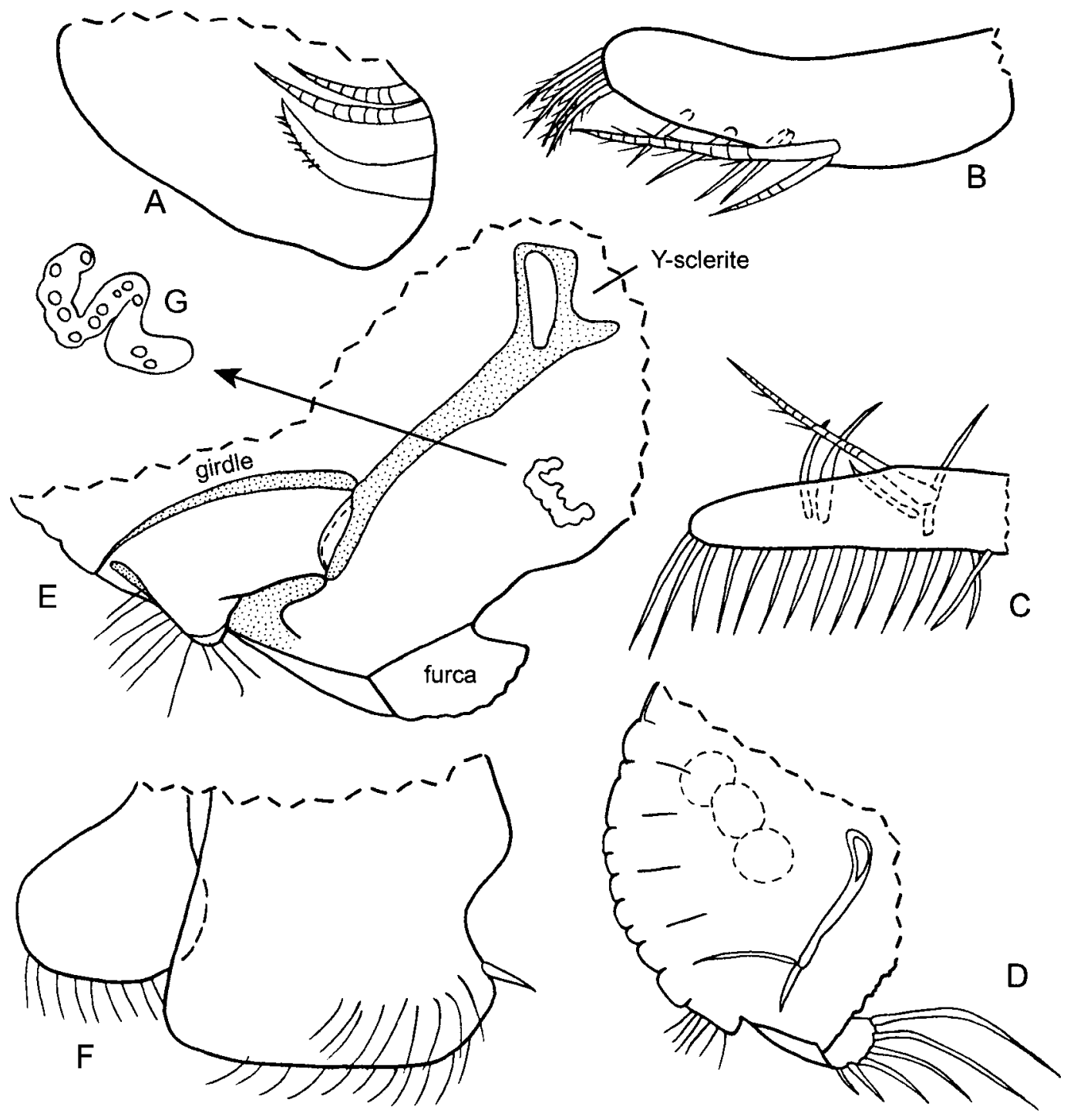

Figure 7. Bruuniella beta, n. sp., holotype, usNm 1023197, adult female: $A$, endite of basis of right mandible, medial view; $B$, comb of left 5 th limb, lateral view; $C$, comb of right 5 th limb, medial view; $D$, posterior of body showing right lamella of furca, right $\mathrm{Y}$-sclerite, right girdle, and eggs (dashed); $E$, posterior of body (sclerites stippled); $F$, upper and lower lips from right side; $G$, ?genitalia or parasite, detail from $E$. (Not all ventral bristles shown in $B$ and $C$; furcal claws not shown in $E$.)

on medial side near dorsal margin. 7th article: a-bristle clawlike with slender tip (claw with minute proximal spines and few spines at tip); b-bristle with 3 or 4 marginal filaments; c-bristle with 5 long marginal filaments. 8th article: d-bristle absent (Figure $6 E$ ); e-bristle bare, about length of a-bristle; f-bristle ori- ented dorsally, with 4 marginal filaments (proximal 3 with minute proximal spines); gbristle with 5 marginal filaments. Total bristles 20. (Note: b-bristle and the g-bristle are identified herein by the former having its base lateral and closer to the a-bristle. This is the reverse of the terminology used by 


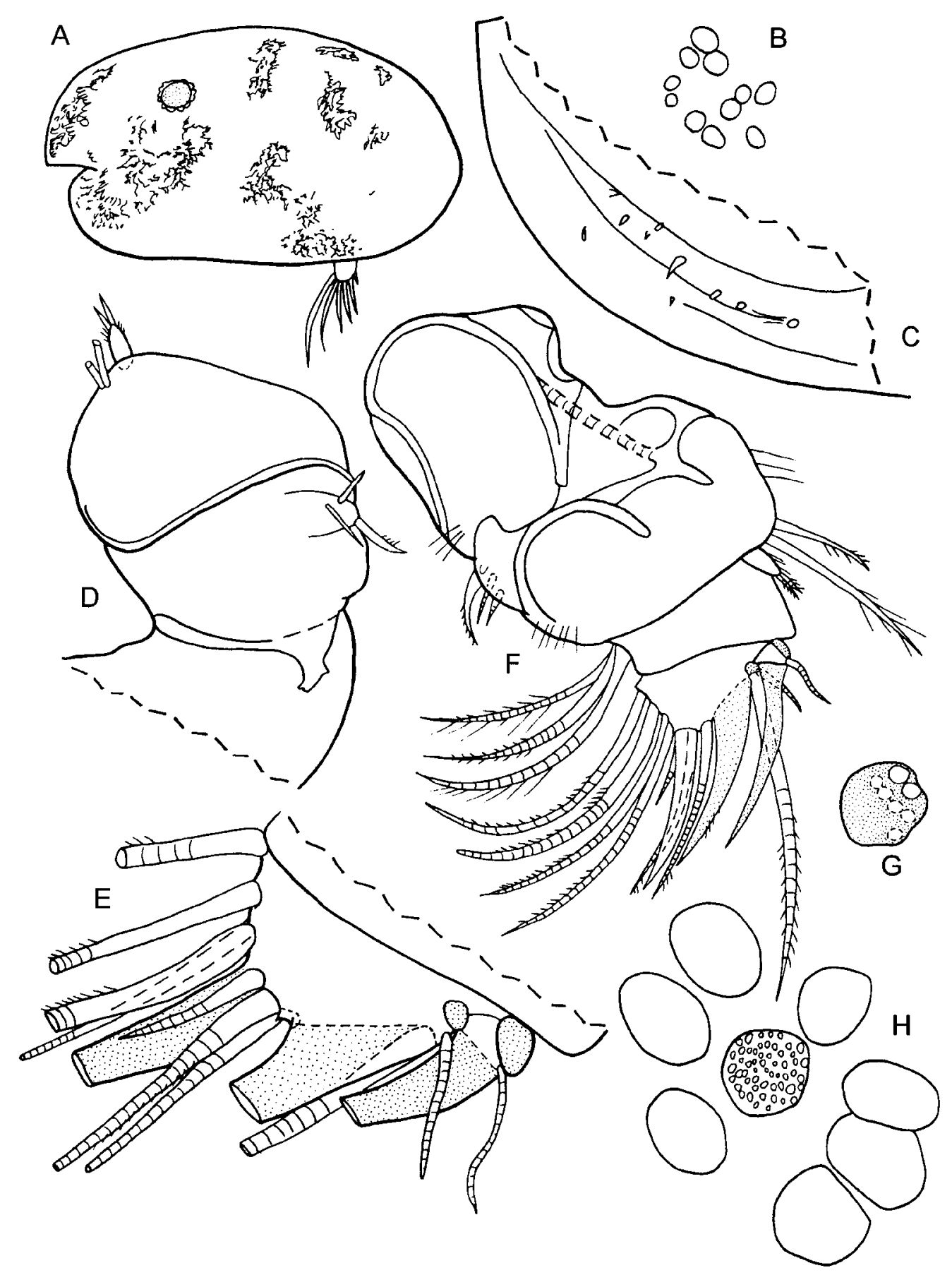

Figure 8. Bruiniella beta, n. sp., paratype, usNm 1023203, adult female: $A$, complete specimen, length $0.89 \mathrm{~mm} ; B$, central adductor muscle attachments of right valve, outside view; $C$, posterior of left valve, inside view (indistinct); $D$, $E$, proximal and distal parts of left mandible, respectively, medial view; $F$, right mandible, lateral view; $G$, lateral eye (many ommatidia obscured by black pigment); $H$, eggs from inside marsupium. 


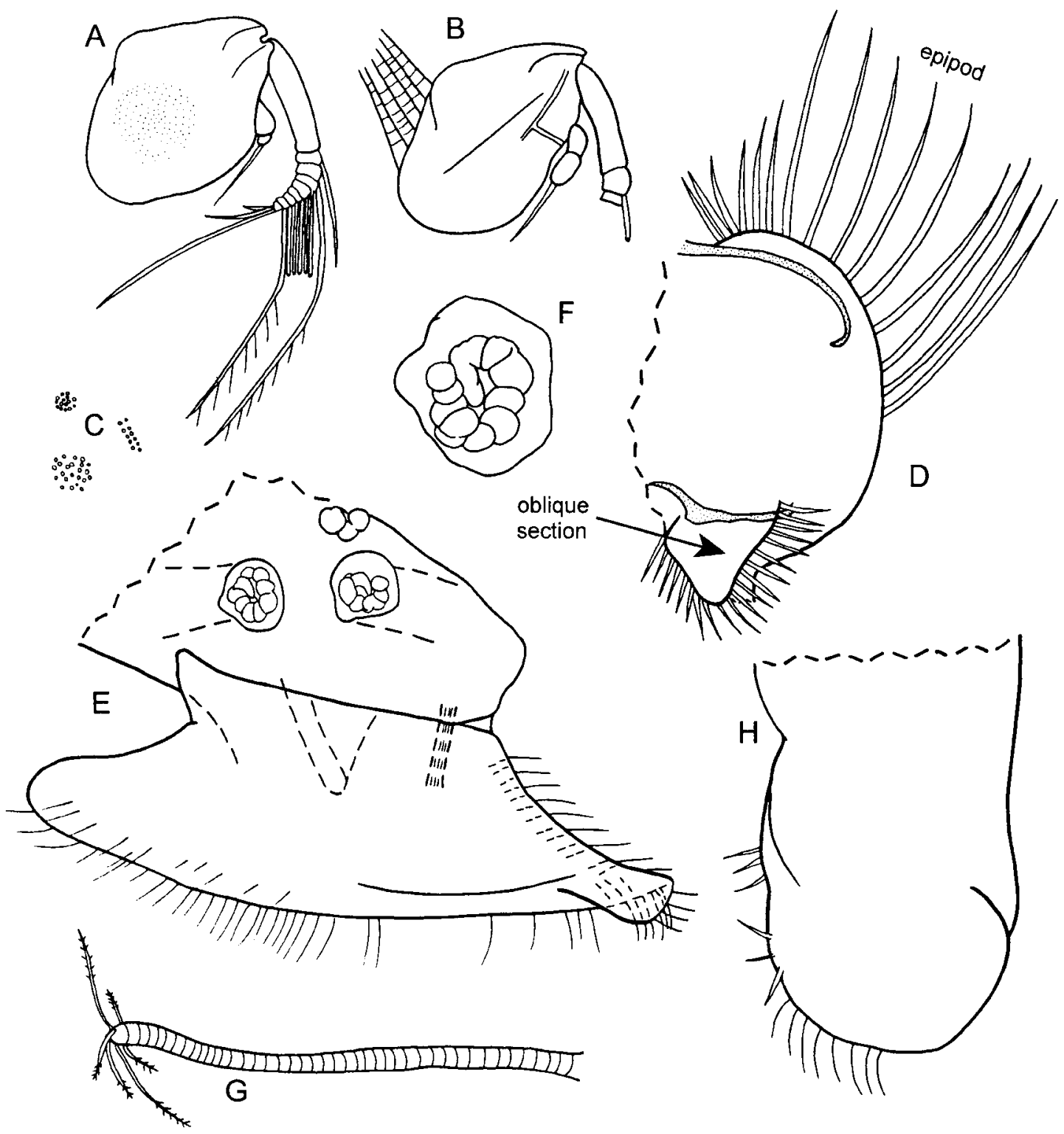

Figure 9. Brunniella beta, n. sp., paratype, usNm 1023203, adult female: $A$, right 2 nd antenna, lateral view; $B$, left 2 nd antenna, medial view; $C$, minute microspheres on protopod of right 2 nd antenna, lateral view (detail from $A$ ); $D$, part of right 5th limb showing epipod and oblique section (not all bristles shown), medial view; $E$, right 6th limb, lateral view; $F$, detail of parasites in $E$; $G$, left 7th limb; $H$, upper lip from left side.

Poulsen [1965:325, fig. 107d'] for B. breviata. L.S.K.'s identification of the bristles is consistent with that used by Poulsen [1965:335, fig. $111 d$ ] for Heptonema keiensis Poulsen, 1965.)

Second antenna (Figures $6 F, 9 A-C$ ): Pro- topod bare. Endopod with 2 articles; 2nd article with long terminal bristle. Exopod with 9 articles without spines; bristle of 2nd article reaching past 9th article, hairs not observed. Bristles of articles 3 to 8 with natatory hairs, 

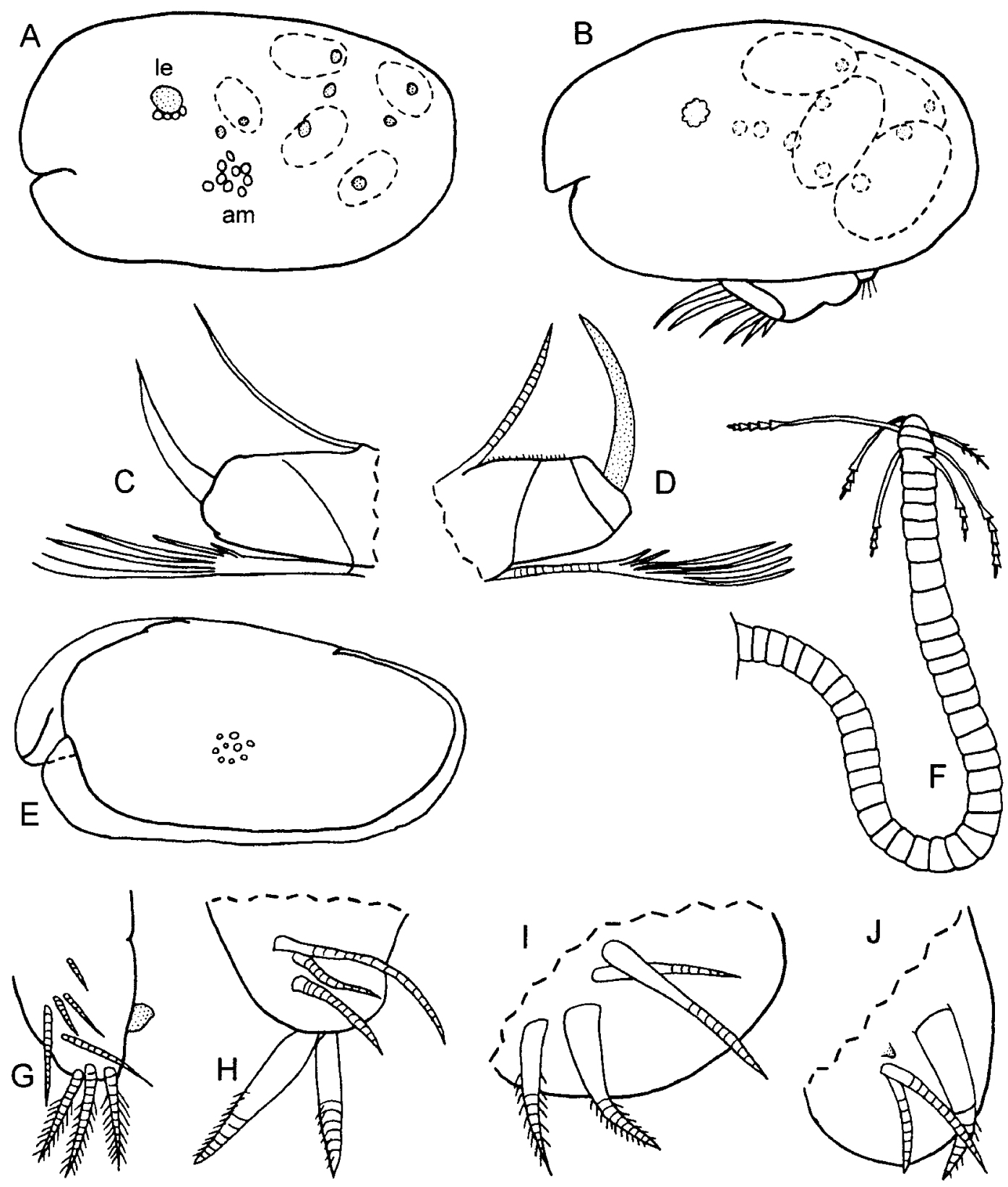

Figure 10. Brunniella beta, n. sp., paratype, usNm 1023209, adult female: $A$, complete specimen (embryos dashed, lateral eyes stippled), length $0.80 \mathrm{~mm}$. Paratype, usNm 1023198, adult female: $B$, complete specimen (embryos and lateral eyes of embryos dashed, latter also stippled), length $0.84 \mathrm{~mm}, C, D$, tip of left and right 1st antennae (not all bristles shown), respectively, lateral view. Paratype, USNM 1023208, adult female: $E$, separated right valve, length $0.83 \mathrm{~mm}$, inside view; F, 7th limb. G-7: ventral medial part of basis of mandible: G, Bruuniella breviata Poulsen, 1965, lectotype, adult female, left limb (from Poulsen 1965: fig. 107g), medial view; H, Bruuniella hazeli Kornicker, 1986, holotype, usnm 152849, adult female, left limb, medial view; I, Brunniella alpha, n. sp., holotype, usNm 158119, A-1 male, left limb, medial view; $\mathcal{F}$, Bruuniella beta, n. sp., holotype, usNm 1023197, adult female, right limb, medial view. 
no spines. 9th article with 3 bristles: 1 long with natatory hairs, 1 medium with faint short spines, 1 short bare. Lateral side of protopod of many specimens with abundant minute reddish disks of unknown origin (Figure $9 C)$. Total bristles 12 .

Mandible (Figures 7A, 8D-F, 107): Coxa endite broken off both females examined (see Figure $19 G$ for complete endite of A-3 instar, which is probably similar to that of adult female). Basis endite with 1 short stout spinous bristle, 2 short slender bare bristles, and minute peg (Figures $8 F, 107$ ). Basis with or without dorsal hairs; dorsal margin with 2 distal spinous bristles; ventral margin with hairs but no bristles. Exopod short with 2 short spinous bristles. Endopod: 1st article with 3 long spinous ventral bristles; 2 nd and 3 rd articles fused, with total of 13 bristles and claws (3 stout claws, 7 long bristles, and 3 short medial bristles) (Figure 8E,F). Total bristles 23 .

Maxilla (Figure 6G): Basis and endopod articles fused. Endites I and II each with 3 bristles. Lateral ventral comb with 56 spoontipped bristles (not shown), and proximal stout bristle with bent tip. Endopod: Inferred 1st article with stout terminal bristle; inferred 2nd article with stout spinous terminal bristle. Epipod missing on limbs of both females examined (probably broken off during dissection). Total bristles 61 .

Fifth limb (Figures 7B,C, 9D): Comb with long exopodial bristle and several shorter bristles on same side (bristles obscured on limbs of both females examined) (Figure $7 B, C)$. Approximate number of bristles: epipod 37 (Figure $9 D$ ), oblique section anterior to epipod 32 (Figure 9D), ventral margin of comb 17 (Figure $7 C$ ), broad surface of comb 5 (Figure 7B,C). Total bristles 91. Count of bristles very approximate.

Sixth limb (Figure 9E,F): Limb with anterior and ventral spines but no bristles; lateral flap broad and bearing spines, but no bristles. Total bristles 0 .

Seventh limb (Figures 9G, 10F): Long with 6 terminal bristles ( 3 on each side); each bristle with 2 to 5 bells. Tip with 1 or 2 opposing minute teeth (not shown). Total bristles 6.

Furca (Figure 7D,E): Each lamella with 5 or 6 claws. Claws with indistinct minute teeth along posterior edges.

Bellonci Organ (Figure 6H): Short bulbous with broadly rounded tip.

Eyes: Medial eye unpigmented, bare (Figure $6 H$ ). Lateral eye with numerous ommatidia and black pigment between ommatidia (exact number of ommatidia obscured by black pigment) (Figures $6 A, 8 A, G, 10 A, B)$.

Gills: Absent.

Lips (Figures $7 F, 9 H$ ): Upper lip rounded, hirsute, with anterior spines and ventral hairs. Lower lip flaplike, hirsute.

Posterior of body (Figure 7D,E): Posterior section ventral to posterior end of girdle with long hairs.

Y-Sclerite (Figure 7D,E): Stout, elongate, with loop at anterior end. Girdle not quite extending to posterior end of body.

Genitalia (Figure 7E,G): Wormlike feature may be genitalia.

Eggs (length, width in $\mathrm{mm}$ ) (no attempt made to orient eggs) (Figures $7 D, 8 H$, $10 A, B)$ : UsNm 1023203 with 8 eggs filled with globules in marsupium: 0.224, 0.172; $0.235,0.187 ; 0.238,0.175 ; 0.192,0.132$; $0.184,0.158 ; 0.194,0.149 ; \quad 0.195,0.182$; $0.229,0.177$. USNM 1023208 with 7 eggs: 0.149, 0.093 (1 egg).

Foreign organisms: Inner side of many valves and outer surfaces of protopod of 2 nd antenna with abundant unidentified microspheres appearing red in transmitted light and reddish brown in reflected light (USNM 1023203, 1023197 with microspheres; USNM 1023209 without microspheres). USNM 1023203 with 3 unidentified coiled organisms within body just proximal to 6th limbs (Figure $9 E, F)$. USNM 1023208 with similar coiled organism inside body; diameter of coil 0.053 $\mathrm{mm}$.

REMARKS CONCERNING USNM 1023208: The carapace of this specimen, an ovigerous female from Station 9, is unusual in having a narrower posterior half in lateral view than other females of the species (Figure 10E). Before examining the appendages, it was thought that it might belong to a different species. The specimen has the usual appendages of $B$. beta except for lacking a furca. It could not be determined whether the poste- 
rior part of the body where the furca usually is attached was sealed. This is mentioned because the absence of the furca and the narrow dorsal half of the carapace could be related; the data are too few to attempt an explanation. The specimen had a wormlike organism inside the body, but other specimens with similar organisms have furcae.

DESCRIPTION OF ADULT MALE (Figures 11-14): Carapace oval in lateral view, with convex posterior margin and convex or linear ventral margin; anterior with incisure, and posterior with slightly projecting caudal process (Figure 11A,B). Carapace without vertical row of hairs near posterior end. (Carapace flimsy and outlines in Figure $11 A, B$ somewhat distorted.)

Carapace size (length, height in $\mathrm{mm}$ ): USNM 1023210: 0.73, 0.41 .

First antenna (Figure 11B,C): 1st article bare. 2nd article with spinous dorsal terminal bristle. Articles 3 and 4 fused. Dorsal margin of inferred article 3 with 3 stout spinous bristles with broad bases, 1 proximal slender spinous bristle with base on margin, and 2 slender bare distal bristles with bases medial to broad bristles. Inferred article 4 with spinous dorsal bristle. Sensory bristle broad with numerous long filaments, with base of bristle on small article appearing to be wedged between article 2 and fused articles 3 and 4. 6th article fused to articles 7 and 8, with short medial bristle. 7 th article: a-bristle clawlike with spines along concave margin; b-bristle with 3 marginal filaments; c-bristle long with 6 marginal filaments. 8th article: d-bristle absent; e-bristle lateral, bare, about 3/4 length of $g$-bristle; f-bristle bent dorsally, with 4 marginal filaments; g-bristle with 5 marginal filaments. Total bristles 16.

Second antenna (Figure 11A,B,D-G): Protopod bare. Endopod with 3 articles: article 1 bare; article 2 with 3 short bristles; article 3 reflexed, with proximal filament and pointed tip. Exopod similar to that of adult female: 1 st article bare; bristle of 2 nd article with ventral spines; long bristles of articles 3-8 with natatory hairs; 9th article with 3 bristles (1 long and 1 short with natatory hairs, 1 very short dorsal, bare). Total bristles 15 .
Mandible (Figures 11 $A$, 12): Coxa endite with spinous ventral branch and slender dorsal branch (tip not resolved) and without bristle at base of branch (Figure 12A,B). Basis: endite with 5 slender bristles (Figure 12A,B); dorsal margin of basis with 2 long distal bristles. Exopod short with few minute subterminal spines and 2 small terminal bristles (Figure 12A). Endopod: 1st article with 3 long spinous bristles ( 2 with long spines, 1 with short spines). 2nd and 3rd articles well defined at dorsal margin by discontinuity in sclerotization along edge but less well defined along ventral margin. 2nd article with 5 slender dorsal bristles and 3 long slender spinous ventral bristles. 3rd article with 2 stout clawlike bristles, 3 long bristles, and 1 short medial bristle near base of ventral claw (Figure $12 A, C)$. Total bristles 26 .

Maxilla (Figure 13A,B): Endite I with 2 or 3 bristles; endite II with 3 bristles. Basis and endopodial articles 1 and 2 fused. Endopod: inferred 1st article with 1 long bristle; 2 nd article with 1 long terminal bristle. Epipod indistinct. Ventral margin of basis with about 52 paddle-tipped bristles (not shown). Total bristles about 59 .

Fifth limb (Figure 13C,D): Comb indistinct, with 1 stout exopod bristle and about 8 bristles close to ventral margins; ventral edge of comb with about 15 bristles (not shown). Epipod with about 47 bristles (not shown). Diagonal with about 15 bristles (not shown). Total bristles very approximately 85 .

Sixth limb (Figure 13E): Ventral edge hirsute but without bristles.

Seventh limb (Figures 13F, 14B,C): Elongate with 4 terminal bristles, 2 on each side with 3 to 5 bells. Terminus with few minute teeth. Limb with 44 rings plus terminus.

Furca (Figure 14A): Each lamella with 5 claws with minute teeth along concave edge. Right lamella anterior to left by width of base of claw 1 .

Bellonci Organ (Figure 13G): Elongate expanding distally.

Eyes: Lateral eye with numerous ommatidia and black pigment; about 9 ommatidia visible along edge. Black pigment extends 


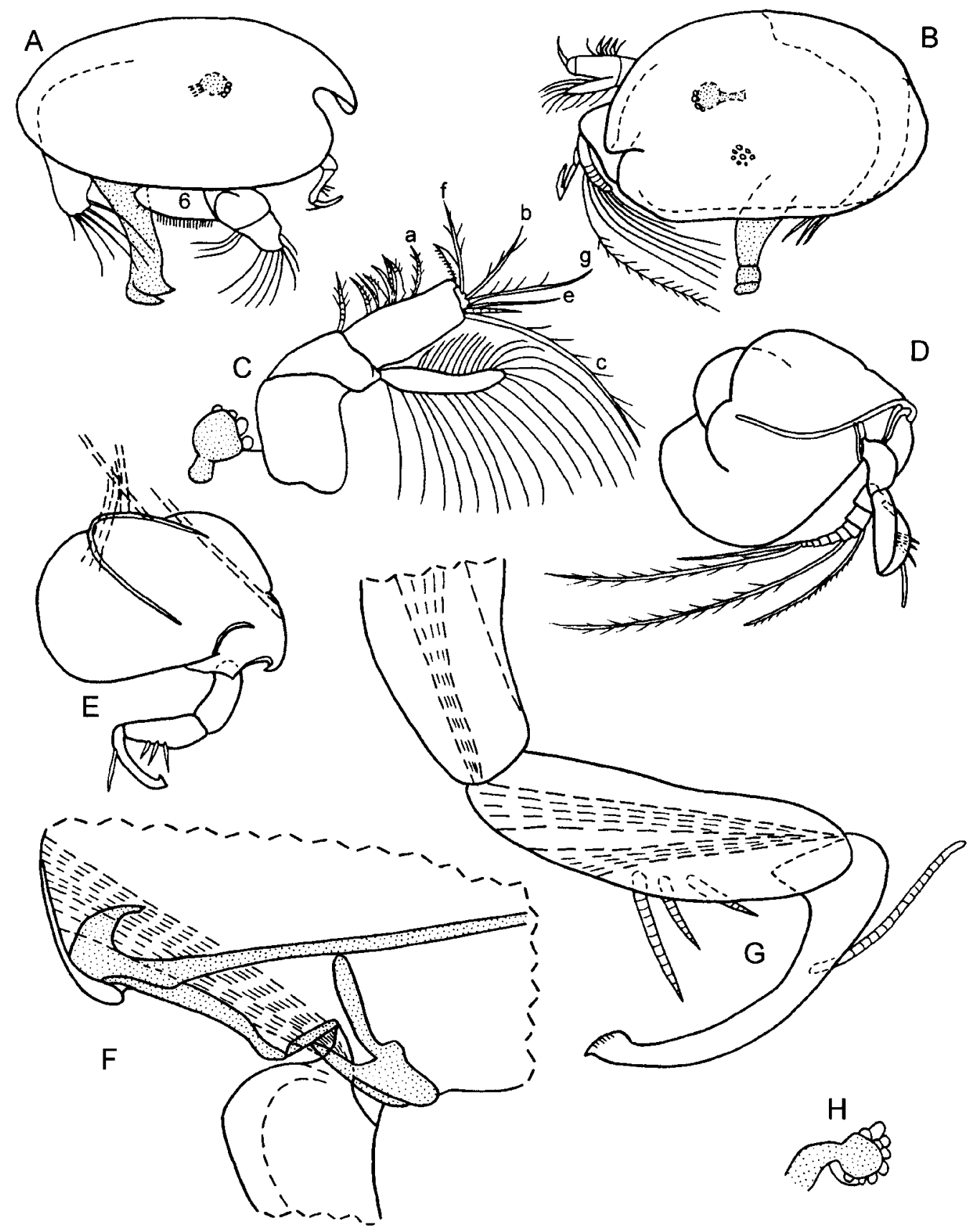

Figure 11. Brunniella beta, n. sp., paratype, usnm 1023210, adult male: $A, B$, complete specimen from right and left sides, respectively, length $0.73 \mathrm{~mm} ; C$, right lateral eye and right 1 st antenna, lateral view; $D$, left $2 \mathrm{nd}$ antenna, medial view (not all bristles shown); $E$, protopod and endopod of right 2 nd antenna, lateral view; $F$, parts of protopod and endopod of right 2 nd antenna, medial view; $G$, endopod left 2 nd antenna, medial view; $H$, left lateral eye. 


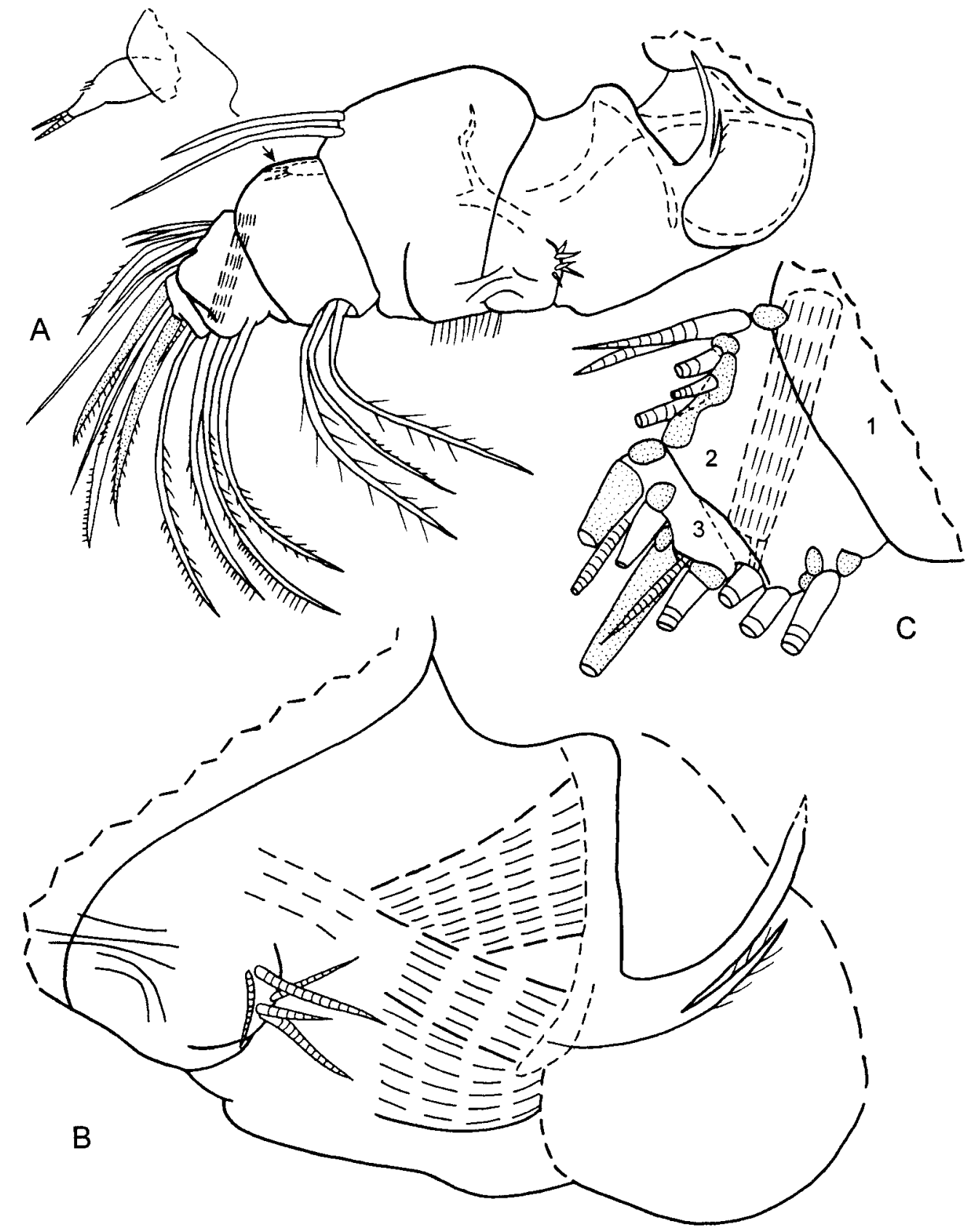

FIgURE 12. Bruuniella beta, n. sp., paratype, usNm 1023210, adult male, right mandible, medial view: $A$, complete limb; $B$, detail of coxa and basis endites; $C$, detail of endopod. 


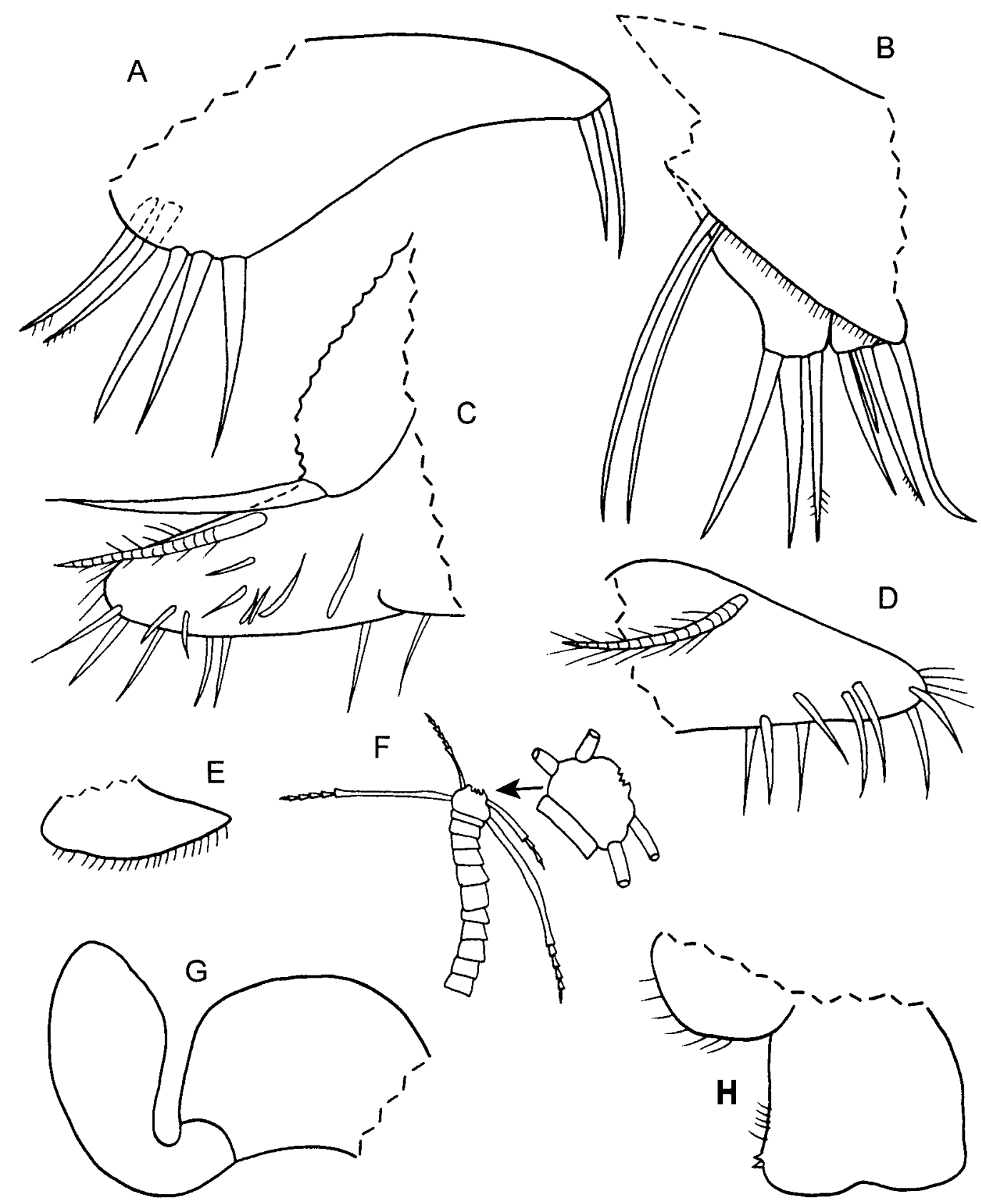

FIgURE 13. Bruuniella beta, n. sp., paratype, usNm 1023210, adult male: $A$, right maxilla, lateral view (not all bristles shown); $B$, endites of left maxilla, lateral view; $C$, left 5 th limb, lateral view (not all bristles shown); $D$, comb of right 5th limb, lateral view (not all bristles shown); $E$, right 6th limb, lateral view; $F, 7$ th limb; $G$, medial eye and Bellonci Organ; $H$, lips. 


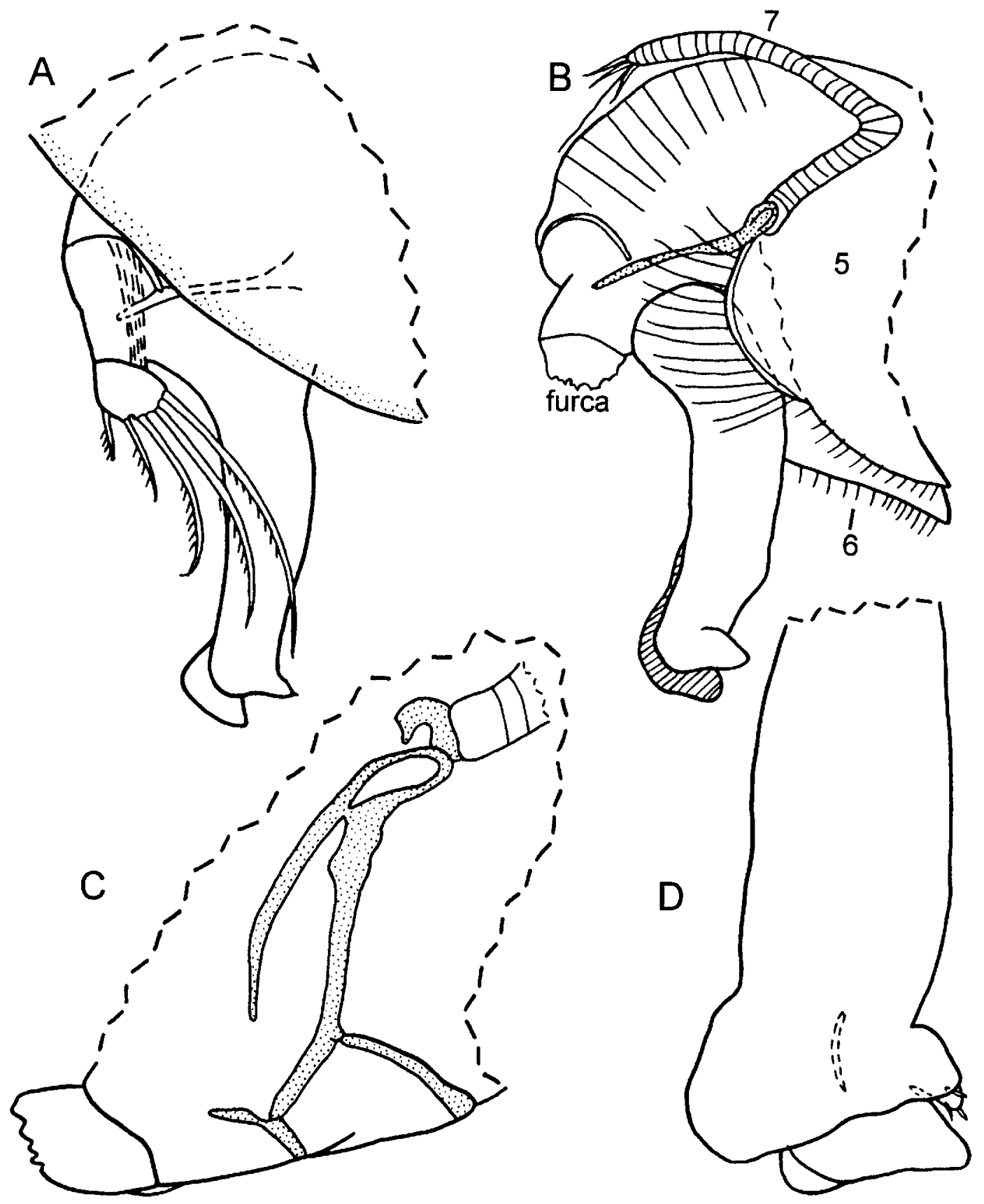

Figure 14. Brunniella beta, n. sp., paratype, usNm 1023210, adult male: $A$, furca and copulatory organ projecting from carapace; $B$, posterior of body from right side showing 5 th, 6 th, and 7 th limbs, copulatory organ, proximal part of furca, and some internal sclerites; $C$, posterior of body from left side showing proximal parts of 7 th limb and furca and internal sclerites (stippled); $D$, detail of copulatory organ, anterior to right. 
posteriorly as narrow bar (Figure $11 A-C, H$ ). Medial eye bare (Figure 13G).

Gills: Absent.

Lips (Figure 13H): Upper lip with $2 \mathrm{mi}-$ nute spines. Lower lip hirsute.

Posterior of body (Figure 14C): Bare.

Y-Sclerite (Figure $14 C$ ): With loop at anterior end; elongate sclerite extends posteriorly from anterior end of $\mathrm{Y}$-sclerite.

Genitalia (Figures 11A,B, 14A,B,D): Elongate, paired, with anterior projection at tip but internal structures not visible; 3 small anterior bristles observed near tips.

Foreign organisms: None.

DESCRIPTION OF A-1 MALE INSTAR (Figures 15, 16): Carapace elongate with slightly convex dorsal and fairly linear ventral margins and deep incisure (Figure 15A).

Central adductor muscle attachments (Figure $15 B$ ): Comprising about 12 ovoid attachments.

Carapace size (length, height in $\mathrm{mm}$ ): USNM 1023204: 0.66, 0.34.

First antenna (Figure 15C): 1st article bare. 2nd article with distal spinous dorsal bristle. 3rd to 5th articles fused. Dorsal margin of inferred 3rd article with 1 spinous proximal bristle, 3 stout bristles with broad proximal part, and 2 slender medial bristles. Inferred 4th article with long slender dorsal bristle and 2 long ventral bristles. Sensory bristle of 5th article with 6 long filaments. 6th article with minute spines along dorsal margin and medial side near dorsal margin, and with short slender terminal medial bristle. 7 th article: a-bristle clawlike, with proximal minute dorsal spines; b-bristle about same length as a-bristle, with 3 marginal filaments; c-bristle long, with 6 marginal filaments. 8th article: d-bristle absent; e-bristle bare, about same length as a-bristle; f-bristle bent dorsally, with 4 marginal filaments; gbristle longer than a-bristle, with 5 marginal filaments. Total bristles 18 .

Second antenna (Figure 15D): Protopod bare. Endopod with 3 elongate articles: article 1 bare; article 2 with 2 short bristles; article 3 with long subterminal bristle. Exopod with 9 articles: article 1 long, bare; article 2 with bristle reaching well past 9th article; articles 3 to 8 each with hirsute long bristle; article 9 with 3 bristles ( 1 short, 1 medium, 1 long hirsute). Total bristles 14 .

Mandible (Figure 15E,F): Coxa endite partly obscured (Figure 15F). Basis endite with 1 short stout spinous bristle, 1 or 2 short slender bare bristles, and minute peg. Basis with 2 distal spinous dorsal bristles. Exopod short with 2 short spinous bristles. Endopod: 1st article with 3 long spinous ventral bristles; 2nd and 3rd articles fused, with total of 13 bristles and claws ( 3 stout claws, 7 long bristles, and 3 short medial bristles). Total bristles 22-23.

Maxilla (Figure 16A): Epipod broad, short, indistinct. Basis and endopod articles fused. Endites I and II each with 3 bristles. Basis with about 55 spoon-tipped bristles and proximal stout bristle with bent tip. Endopod: inferred articles 1 and 2 each with 1 stout terminal bristle. Approximate total bristles 64 .

Fifth limb: Comb with long exopodial bristle and 4 bristles on broad surface; ventral margin of comb with about 25 bristles; oblique edge of section proximal to comb with about 15 bristles; epipod with 46 bristles. Count very approximate 90 .

Sixth limb (Figure 16B): Similar to that of adult female. With hairs but no bristles.

Seventh limb (Figure 16C): Long with 4 tapered terminal bristles, 2 on each side (2 short bristles with 1 bell, 2 long bristles with 3 bells); tip bare. Total bristles 4 .

Furca (Figure 16D): Each lamella with 5 claws.

Bellonci Organ (Figure 16E): Similar to that of adult female.

Eyes: Lateral eye with many ommatidia and black pigment between and covering ommatidia except along edges (Figures 15 A, $16 F$ ). Medial eye bare (Figure 16E).

Gills: Absent.

Lips: Upper lip similar to that of adult female, with anterior spines (Figure 16G).

Posterior of body (Figure 16H): Similar to that of adult female.

Y-Sclerite (Figure 16H): With looped anterior end.

Genitalia: Not observed with certainty.

Foreign organisms: USNM 1023204 with reddish microspheres similar to those of some adult females on inner side of valves, 

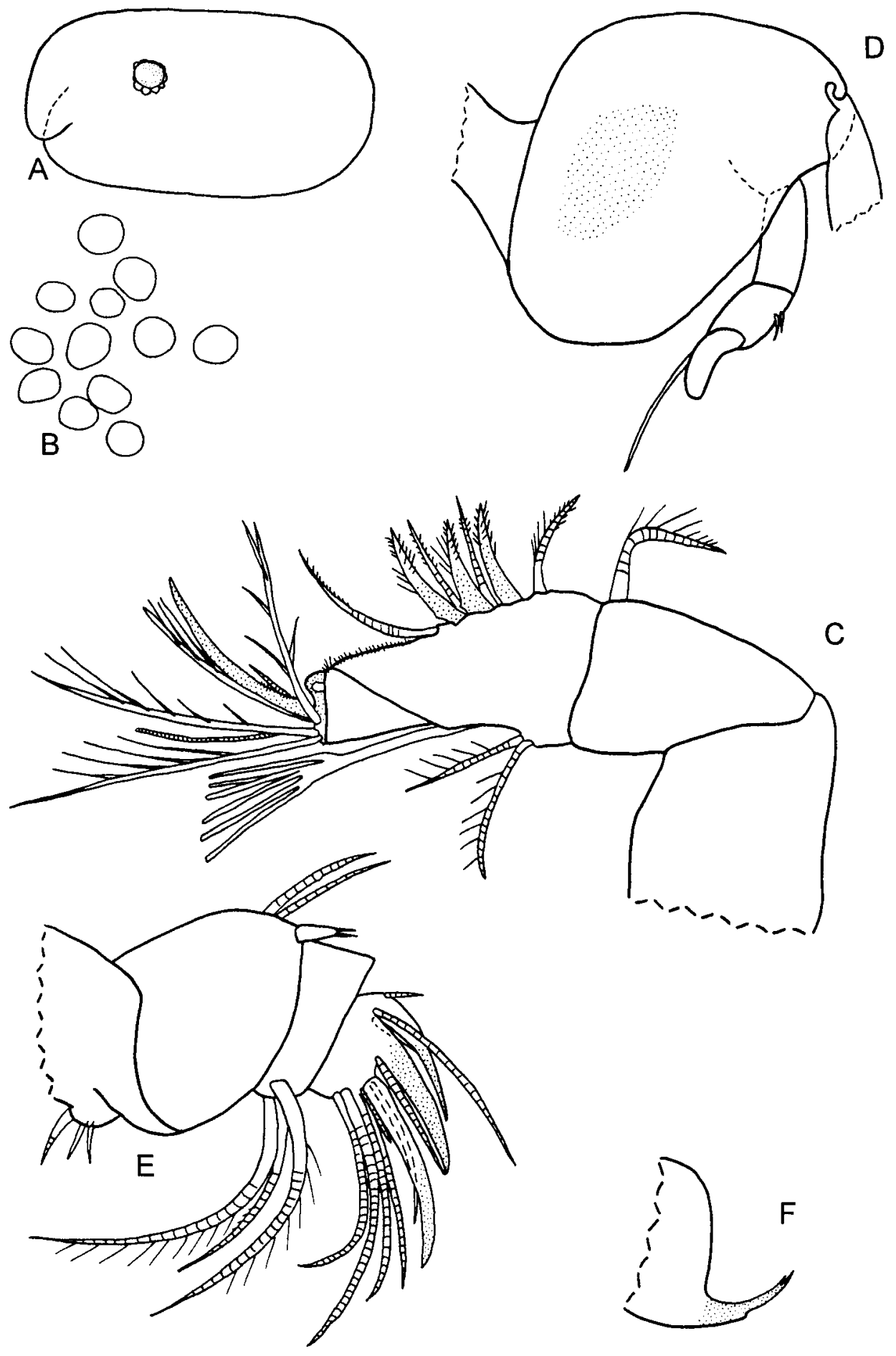

Figure 15. Bruuniella beta, n. sp., paratype, usnm 1023204, A-1 male: $A$, complete specimen, length $0.66 \mathrm{~mm} ; B$, central adductor muscle attachments of right valve, outside view; $C$, left 1st antenna, lateral view; $D$, protopod (microspheres stippled) and endopod of right 2nd antenna, lateral view; $E$, right mandible, lateral view; $F$, coxa endite of mandible. 


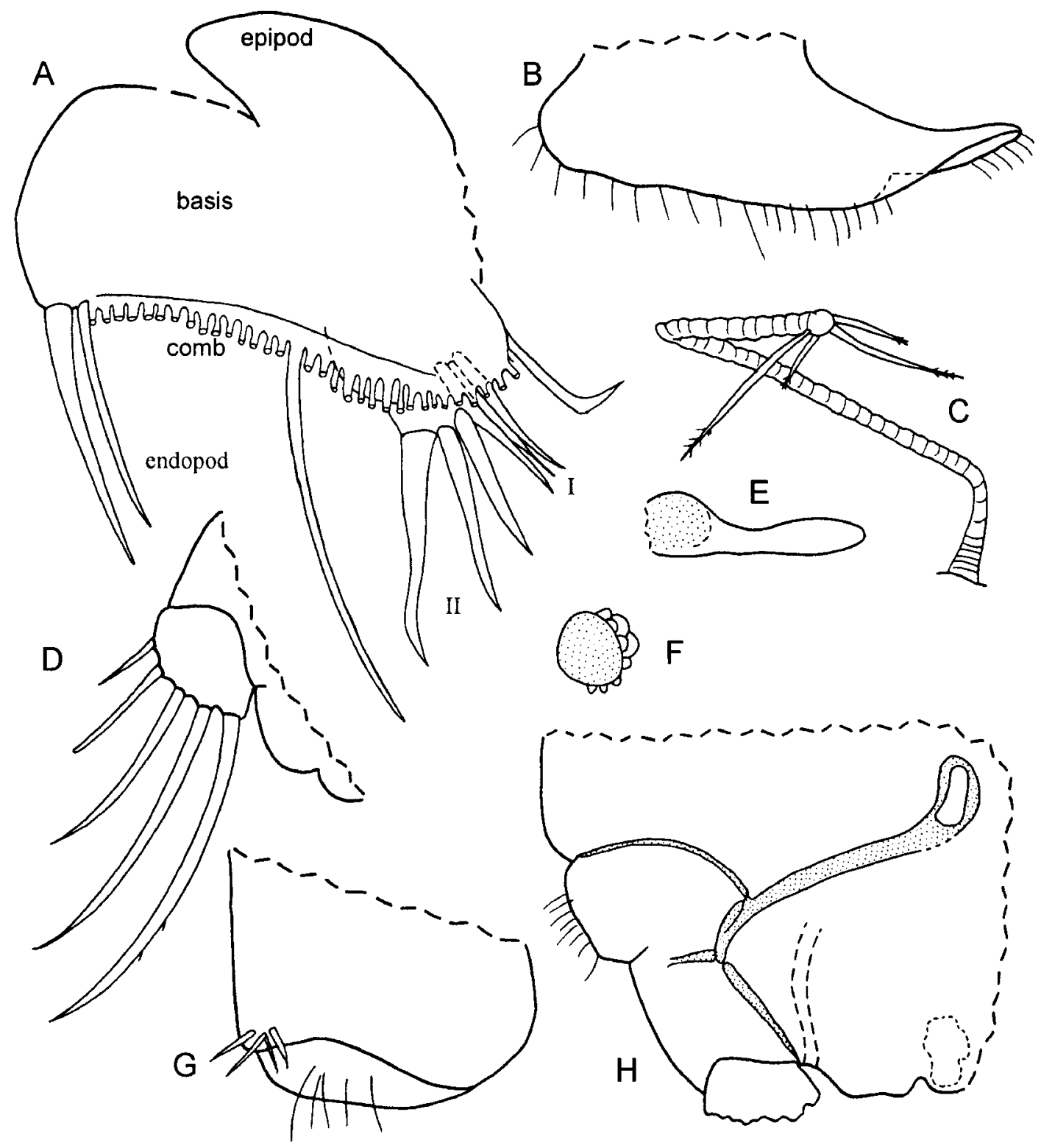

FIgURE 16. Bruiniella beta, n. sp., paratype, usNm 1023204, A-1 male: $A$, left maxilla (only proximal part of comb bristles shown), lateral view; $B$, 6th limb; $C$, 7th limb; $D$, right lamella of furca, lateral view; $E$, medial eye and Bellonci Organ; $F$, left lateral eye (not all ommatidia shown); $G$, upper lip from left side; $H$, posterior of body from right side (internal sclerites stippled).

on lateral side of protopod of 2nd antenna (Figure $15 D$ ), on body ventral to lateral eye, and on posterior end of body.

DESCRIPTION OF A-2 MALE INSTAR (Figures 17, 18): Carapace elongate with convex sloping dorsal margin and linear ventral margin (Figure 17 $A$ ).

Central adductor muscle attachments (Figure $17 B$ ): Consisting of about 14 oval attachments. 


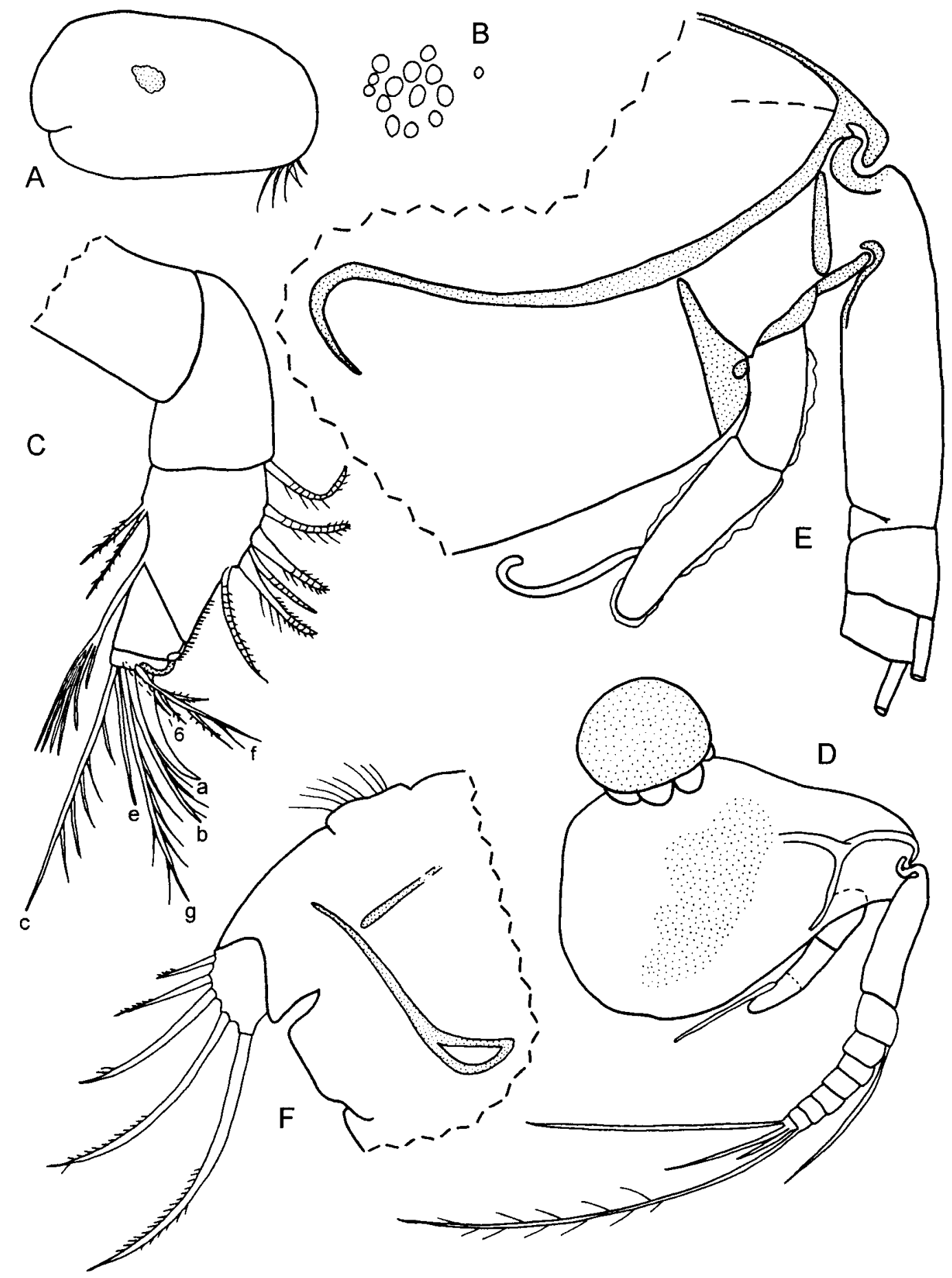

Figure 17. Bruuniella beta, n. sp., paratype, usNm 1023206, A-2 male: $A$, complete specimen, length $0.59 \mathrm{~mm} ; B$, central adductor muscle attachments of left valve, outside view; $C$, right 1st antenna, lateral view; $D$, right 2 nd antenna (not all bristles shown) and right lateral eye (not all ommatidia shown), lateral view; $E$, part left 2 nd antenna, medial view; $F$, posterior of body from right side (internal sclerites stippled). 
Carapace size (length, height in $\mathrm{mm}$ ): USNM 1023206: 0.59, 0.35 .

First Antenna (Figure 17C): 1st article bare. 2nd article with distal dorsal spinous bristle. Articles 3 to 5 fused. Dorsal margin of inferred 3rd article with proximal spinous bristle, 2 stout spinous bristles, and 1 slender medial bristle. Inferred 4th article with 2 spinous ventral bristles and 1 spinous dorsal bristle. Sensory bristle of 5 th article with 6 filaments (proximal filament fairly short, about $1 / 3$ length of terminal filament). 6th article fused to 7 th on medial side, with minute spines along dorsal margin and on medial side near dorsal margin, and with short medial bristle. 7th article: a-bristle clawlike, with minute proximal dorsal spines, b-bristle with 3 marginal filaments, c-bristle with 5 marginal filaments. 8th article: d-bristle absent; e-bristle bare, about same length as abristle; f-bristle bent dorsally, with 4 marginal filaments (proximal 3 with marginal spines); $\mathrm{g}$-bristle with 5 marginal filaments. Total bristles 16.

Second antenna (Figure 17D,E): Protopod bare. Endopod with distinct suture between 1st and 2nd articles and no suture between 2nd and inferred 3rd articles; inferred article 3 with long marginal bristle. Exopod with 9 articles: article 1 bare; article 2 with bristle reaching past 9th article; articles 3-8 each with long bristle with marginal hairs; article 9 with 3 bristles ( 1 medium, 2 short). Total bristles 12 .

Mandible (Figure 18A-C): Coxa endite slender, scythe-shaped; dorsal part distinct, ventral part with indistinct ventral edge (tip of endite indistinct); ventral process represented by minute proximal projection (ventral process broken off) (Figure 18C). Basis endite with proximal peg and 3 bristles (2 slender bare, 1 broad spinous) (Figure 18B). Basis, exopod, and endopod similar to those of adult female. Total bristles 23.

Maxilla (Figure 18D,E): Epipod short. Endite I with 2 or 3 bristles; endite II with 3 bristles. Comb with 47 bristles plus proximal bent bristle. Articles 1 and 2 of endopod fused, each with 1 terminal bristle. Approximate total bristles 55 .

Fifth limb (Figure 18F): Comb with 1 long exopod bristle and about 3 short bristles on broad surface. Ventral margin of comb with about 19 spinous bristles (not shown); oblique section with about 14 spinous bristles. Epipod with about 40 spinous bristles (not shown). Approximate total bristles 77 .

Sixth limb (Figure 18G): Similar to that of adult female.

Seventh limb (Figure 18H): Limb much shorter than that of A-1 male, with 2 tapered terminal bristles, 1 on each side, each with 1 bell; terminal end of limb bare.

Furca (Figure 17F): With 5 claws on each lamella.

Bellonci Organ (Figure 18I): Similar to that of adult female.

Eyes: Lateral eye with many ommatidia and black pigment (Figure 17A,D). Medial eye bare, without color (Figure 18I).

Gills: Absent.

Lips: Upper lip with ventral hairs (Figure 187).

Posterior of body (Figure 17F): With hairs along posterior section ventral to posterior end of girdle.

Y-Sclerite (Figure 17F): With loop at anterior end.

Genitalia: Absent.

Foreign organisms: With unicellular reddish microspheres inside carapace, on lateral side of protopod of 2nd antenna (Figure $17 D)$, and on posterior part of body.

DESCRIPTION OF INSTAR A-3 (SEX UNKNOWN) (Figures 19, 20): Carapace with convex dorsal margin and linear or slightly concave ventral margin; specimens vary in outline (Figures 19A, 20C).

Central adductor muscle attachments: With about 12 oval attachments.

Carapace size (length, height in $\mathrm{mm}$ ): USNM 1023207: 0.50, 0.32. USNM 1023204: $0.51,0.27$.

First antenna (Figures 19B, 20D): 1st article bare. 2nd article with distal dorsal spinous bristle. 3rd to 5th articles fused. Dorsal margin of inferred 3rd article with 2 stout bristles. Inferred 4th article with distal dorsal bristle and 1 ventral bristle. Sensory bristle of 5 th article with 6 filaments (2 terminal). 6th article with short terminal medial bristle (not shown). 7th article: a-bristle clawlike; 


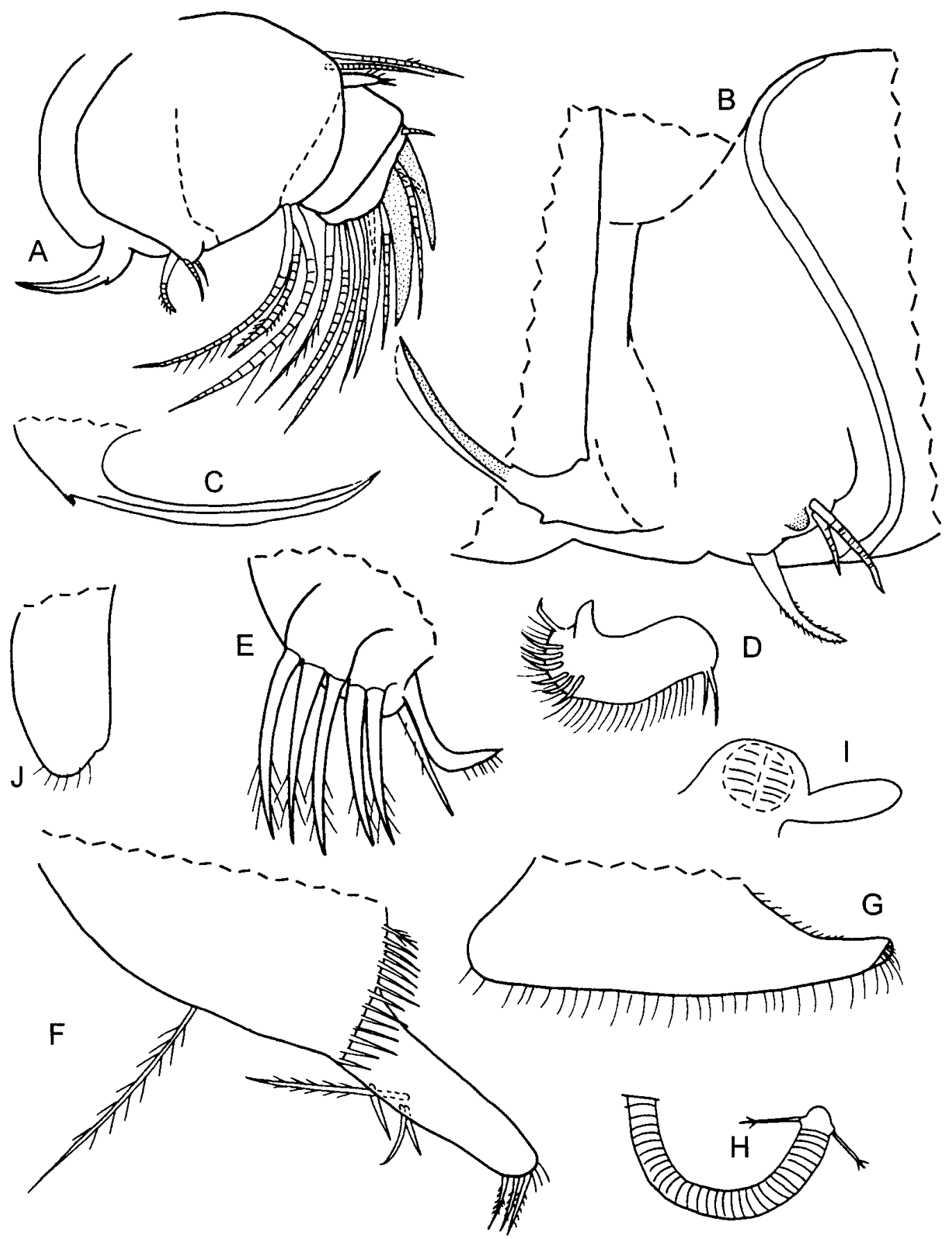

FIgURE 18. Bruuniella beta, n. sp., paratype, usNm 1023206, A-2 male: $A$, right mandible, lateral view; $B$, coxa and basis endites of left mandible, medial view; $C$, coxa endite of right mandible, medial view; $D$, left maxilla, medial view; $E$, endites of right maxilla, medial view; $F, 5$ th limb (not all bristles shown); $G$, left 6 th limb, medial view; $H, 7$ th limb; $I$, medial eye and Bellonci Organ; $\mathcal{F}$, upper lip, anterior to right. 


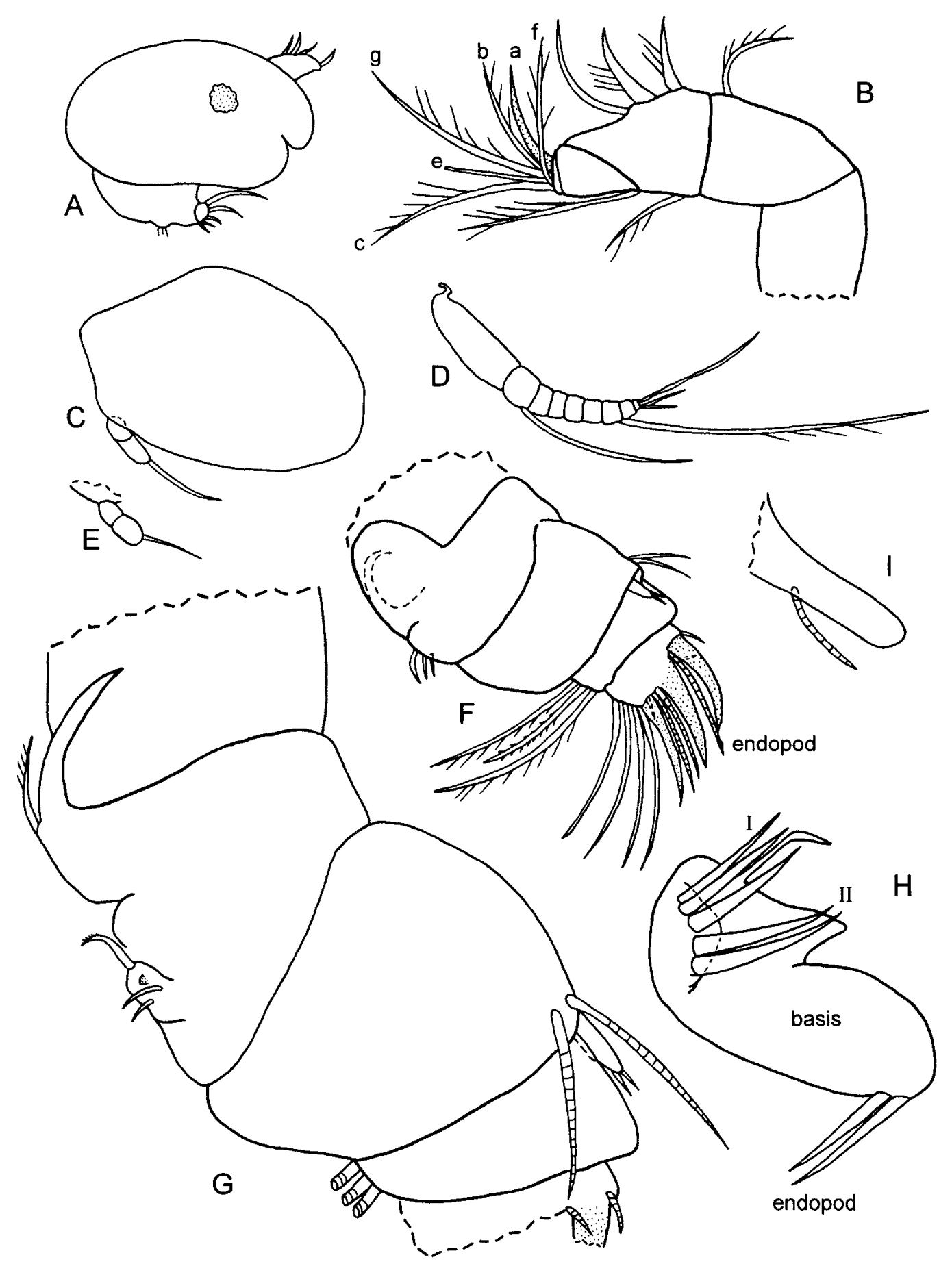

Figure 19. Bruuniella beta, n. sp., paratype, usNm 1023207, A-3 instar (sex unknown): $A$, complete specimen, length $0.50 \mathrm{~mm} ; B$, left 1st antenna, lateral view; $C$, protopod and endopod of left 2nd antenna, lateral view; $D$, exopod of left 2nd antenna, lateral view (not all bristles shown); $E$, endopod of right 2 nd antenna, medial view; $F$, right mandible, lateral view; $G$, proximal part of left mandible, medial view; $H$, left maxilla, medial view (endite bristles unnaturally bent upward) (comb bristles not shown); $I$, comb of 5 th limb (not all bristles shown). 

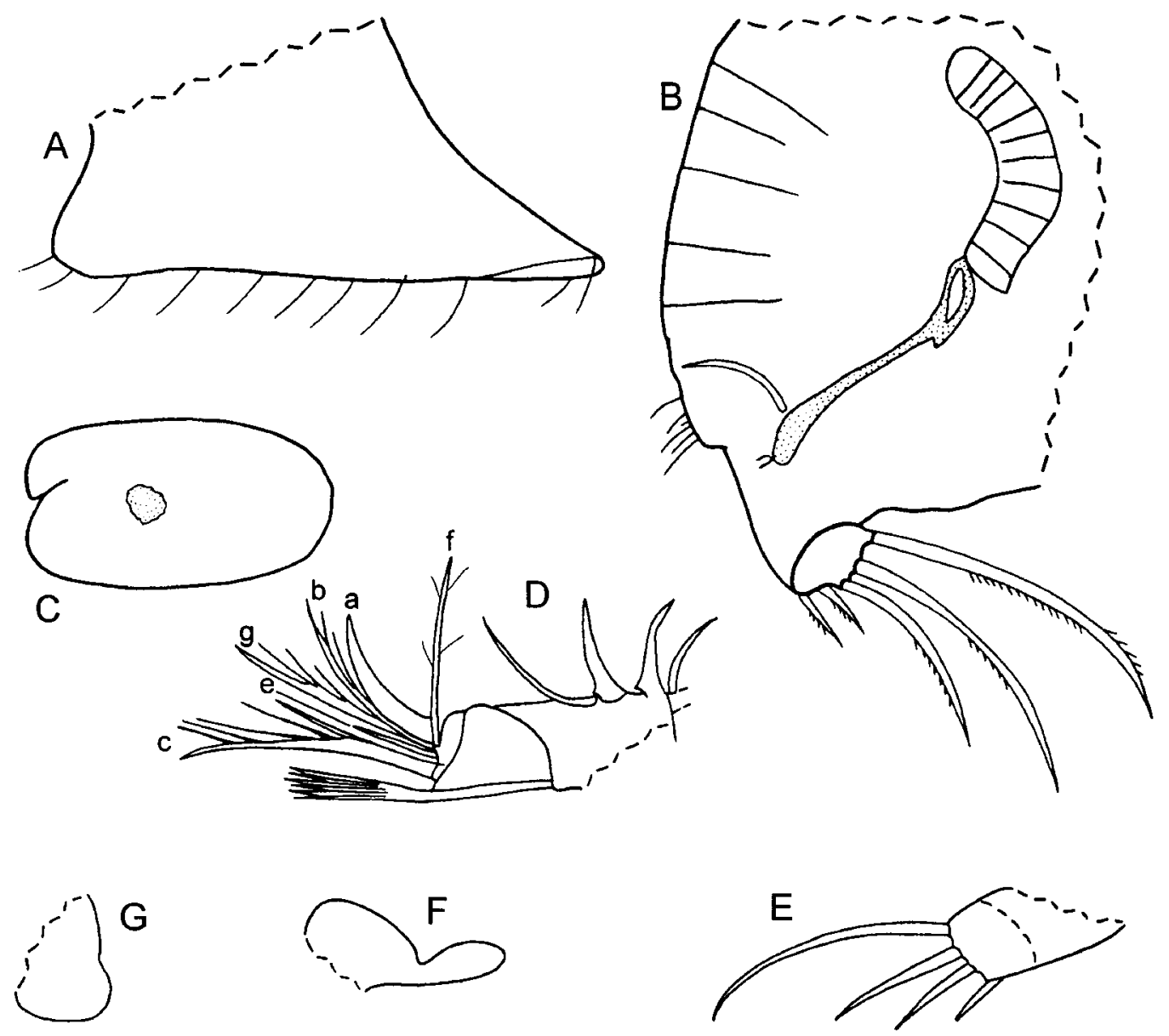

Figure 20. Bruuniella beta, n. sp., paratypes, A-3 instars (sex unknown): usnm 1023207: $A$, left 6th limb, medial view; $B$, posterior of body from right side showing right lamella of furca, right 7 th limb, and internal sclerites (stippled). usNM 1023204: $C$, complete specimen, length $0.51 \mathrm{~mm} ; D$, part left 1 st antenna, lateral view (not all filaments shown on bristles); $E$, left lamella of furca, lateral view; $F$, medial eye and Bellonci Organ; $G$, upper lip from right side.

b-bristle with 3 marginal filaments; c-bristle with 5 marginal filaments. 8th article: dbristle absent; e-bristle bare, about same length as a-bristle; f-bristle bent dorsally, with 4 marginal filaments; g-bristle with 5 marginal filaments. Total bristles 12 .

Second antenna (Figure 19C-E): Protopod bare. Exopod with 9 articles: article 1 bare; articles 2-8 each with long bristle; 9th article with 3 bristles (2 short). Endopod with indistinct suture between articles 1 and 2 ; article 2 with slightly off-center terminal bristle. Total bristles 12 .
Mandible (Figure 19F,G): Coxa endite slender scythe-like, with spinous ventral branch. Basis endite with 3 bristles (1 stout spinous, 2 slender bare) and small peg. Exopod and endopod similar to those of adult female. Total bristles 23.

Maxilla (Figure 19H): Epipod short. Endite I with 1 or 2 bristles; endite II with 3 bristles. Basis and endopod fused. Basis with 38 spoon-tipped bristles (not shown) and 1 proximal bristle with bent tip. Endopod: Inferred 1st and 2nd articles each with terminal bristle. Total bristles 45 or 46 . 
Fifth limb (Figure 19I): Well developed. Comb with 1 exopod bristle. Margin of comb and vertical section with about 19 bristles. Epipod with about 20 bristles. Very approximate total bristles 40 .

Sixth limb (Figure 20A): Similar to that of adult female.

Seventh limb (Figure 20B): Short, bare.

Furca (Figures 19A, 20E): Five claws on right lamella, 4 on left.

Bellonci Organ (Figure 20B): Similar to that of adult female.

Eyes: Lateral eye with many ommatidia and black pigment (Figures 19A, 20C). Medial eye similar to that of adult female (Figure 20F).

Gills: Absent.

Lips (Figure 20G): Upper lip evenly rounded.

Posterior of body (Figure 20B): Hairs on posterior section ventral to posterior end of girdle.

Y-Sclerite (Figure 20B): With looped anterior end.

Genitalia: Absent.

Foreign organisms: Reddish unicellular microspheres within carapace and on lateral surface of protopod of 2nd antenna.

DESCRIPTION OF EMBRYO TAKEN FROM INSIDE SHELl OF FEMALE (Figure 21): Oval in lateral view (Figure 21A,B), with anterior incisure (Figure 21A-C). (Appendages studied are those of USNM 1023199 from adult female USNM 1023198.)

Carapace size (length, height in $\mathrm{mm}$ ): USNM 1023201 from USNM 1023198: 0.268, 0.197 . USNM 1023199 about same size as USNM 1023201.

First antenna (Figure 21D): Segmentation indistinct. Articles 1 and 2 appearing fused, and suture between articles 2 and 3 barely visible. Articles 3 to 6 fused. Inferred articles 3 or 4 with spinous dorsal bristle (3 stout proximal spines shown on inner side of bristle could actually be based on article). Article 5 with long, bare, ringed, ventral bristle. Bristles of articles 6 to 8 indistinct. No bristle observed on 6th article. 7 th article: a-bristle broad with minute proximal dorsal spines; cbristle long bare. 8th article with 2 long bare bristles (possibly more, but exact number could not be resolved). Dorsal margins of articles 5 and 6 with minute spines.

Second antenna (Figure 21E): Protopodite bare. Endopod with 2 articles; terminal bristle on article 2 not observed (possibly not resolved). Exopod with 9 articles: article 1 bare; article 2 with medium-length bristle; articles 3 to 8 with long bristles; 9th article with 3 bristles ( 2 short); hairs not observed on bristles (possibly not resolved).

Mandible (Figure 21F): Limb studied is attached to body on slide, partly obscured and details difficult to resolve. Illustrated limb very approximate.

Maxilla (Figure 21G): Limb studied is attached to body on slide and mostly obscured. With 2 bristles visible at distal end, and 1 proximal bristle ventral to them; proximal part of limb obscured.

Fifth limb: Limb studied is attached to body on slide; only the epipod could be resolved (Figure 21H).

Sixth limb: Not identified with certainty. Only anterior part tentatively identified as right 6th limb visible on posterior part of mounted specimen bearing furca (Figure 21I). No bristles or spines observed on visible part.

Seventh limb: Absent.

Furca (Figure 217): (Including both lamellae) with total of 4 indistinct, long, flexible, hirsute, unringed bristles.

Bellonci Organ: Not observed with certainty.

Eyes: Lateral eye well developed, with black pigment and 6 ommatidia visible along edge (Figure $21 A, K$ ). Medial eye about same size as lateral eye, colorless.

Gills: Absent.

Lips: Obscured on specimen mounted on slide.

Posterior of body (Figure 217): With spines dorsal to furca and longer spines on small posterodorsal shelf.

Y-Sclerite (Figure 217): Not observed with certainty.

Genitalia: Absent.

DISCUSSION OF SIGNIFICANCE OF EMbryo within carapace: The long spinous bristles on the furca are unlike the claws usually present on the 1st free-living instar of 


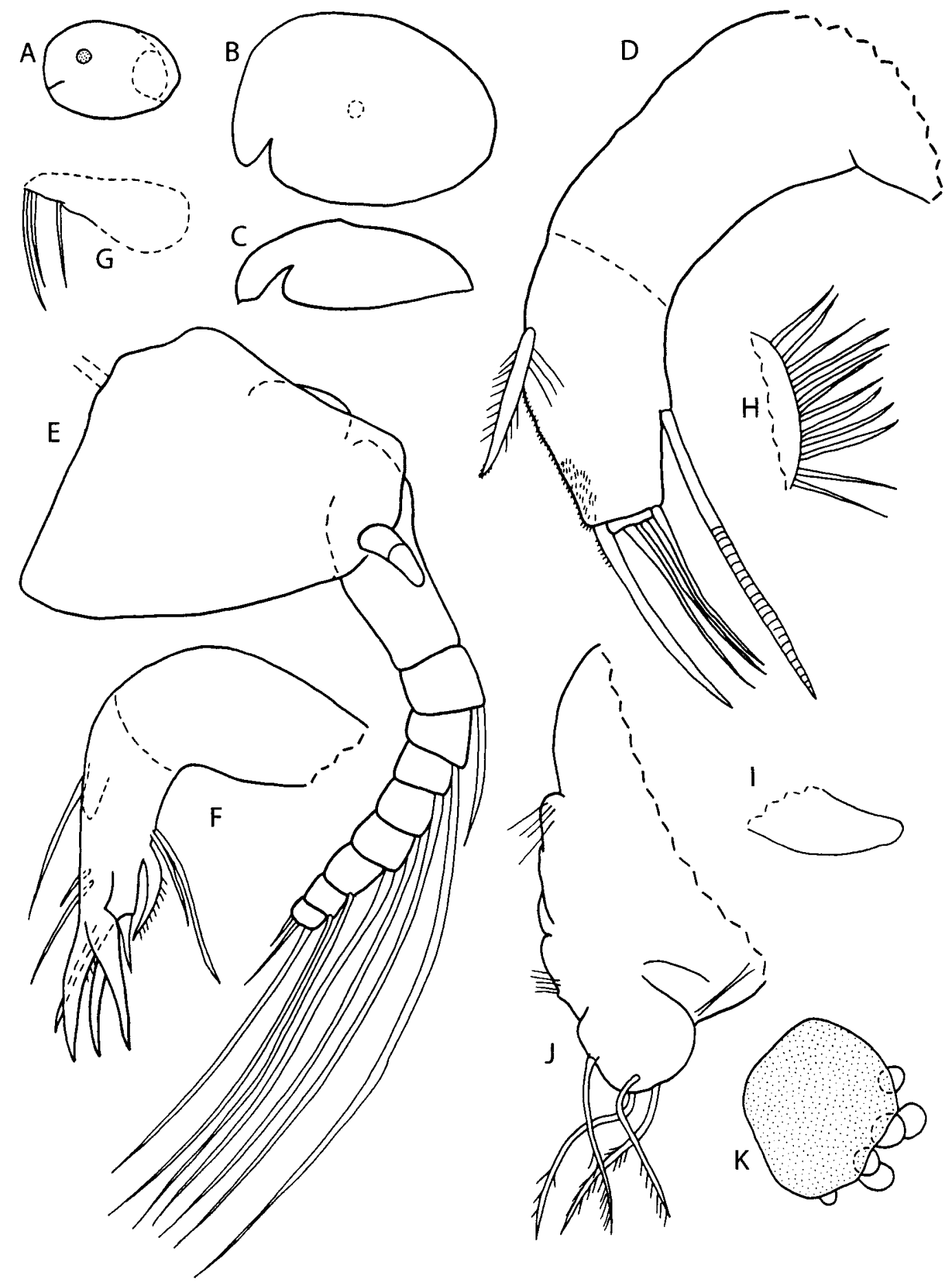

Figure 21. Bruuniella beta, n. sp., paratype, embryos from adult female, USNM 1023198: UsNm 1023201: $A$, complete specimen, length $0.268 \mathrm{~mm}$. USNM 1023199: $B$, left valve of carapace with body removed (drawn at twice magnification of carapace in $A$ ); $C$, ventral view of left valve in $B ; D$, left 1st antenna, lateral view; $E$, left 2 nd antenna, medial view; $F$, right mandible, medial view; $G$, left maxilla, lateral view; $H$, part of epipod of left 5 th limb, lateral view; $I$, right 6 th limb (anterior to right), lateral view; $\mathcal{F}$, posterior of body from right side showing bristles on furca; $K$, lateral eye. 
TABLE 1

Approximate Number of Bristles and Claws on Each Appendage of Stages of Species of Bruuniella and Female Parasterope pacifica

\begin{tabular}{|c|c|c|c|c|c|c|c|c|}
\hline \multirow[b]{2}{*}{ Stage } & \multicolumn{8}{|c|}{ Appendage } \\
\hline & 1st ant. & 2nd ant. & Mnd. & Max. & 5th $\operatorname{limb}$ & 6th $\operatorname{limb}$ & 7th $\operatorname{limb}$ & Furca \\
\hline \multicolumn{9}{|c|}{ Bruuniella beta } \\
\hline Adult $M$ & 16 & 15 & 26 & 59 & 85 & 0 & 4 & 5 \\
\hline Adult F & 20 & 12 & 23 & 61 & 91 & 0 & 6 & 6 \\
\hline A-1 M & 18 & 14 & $22-23$ & 64 & 90 & 0 & 4 & 5 \\
\hline A-2 M & 16 & 12 & 23 & 55 & 77 & 0 & 2 & 5 \\
\hline A-3 (sex ?) & 12 & 12 & 23 & $45-46$ & $40 ?$ & 0 & 0 & $4-5$ \\
\hline \multicolumn{9}{|c|}{ Bruuniella alpha } \\
\hline A-1 M & 18 & 15 & 23 & 60 & 85 & 0 & 4 & 5 \\
\hline \multicolumn{9}{|c|}{ Bruuniella breviata } \\
\hline Adult F & 20 & 12 & 27 & - & - & 17 & 6 & 8 \\
\hline A-2 F & 16 & 12 & 24 & - & - & - & 4 & 5 \\
\hline \multicolumn{9}{|c|}{ Bruuniella bazeli } \\
\hline Adult F & 20 & 12 & 25 & 62 & - & 0 & 6 & 7 or 8 ? \\
\hline \multicolumn{9}{|c|}{ Parasterope pacifica } \\
\hline Adult $\mathrm{F}$ & 20 & 14 & 39 & 99 & 139 & 22 & $6^{*}$ & $8-9$ \\
\hline
\end{tabular}

Note: Bristles of maxilla and 5th limbs of some specimens obscured and number of bristles given very approximate. Mnd., mandible; Max, maxilla; F, female; M, male; _-, number of bristles unknown.

${ }^{*}$ If terminal teeth were included, number would be 24 .

members of the family (see Hiruta 1979: fig. 10:5), which suggests that the specimen described here has not reached that stage. Although it may be an unextruded 1st instar, it is interpreted to be an embryo. No similar free-living specimens were in this collection, which does not contain free-living specimens younger then the A-3 stage. The presence of limbs 1 to 5 , and possibly 6 , on the specimen indicates that the 1st free-living instar has more than three appendages, as found in Podocopa. Tseng (1975:104) observed that the 1st free-living stage of the halocyprid Eunconchoecia elongata Müller bears three appendages (1st and 2nd antennae and mandible) and that the maxilla is added in the 2 nd instar. The presence of at least five appendages on the specimen of $B$. beta obtained from within the carapace of an adult female shows that the ontogeny of $B$. beta differs from that of E. elongata. Poulsen (1962:35, table 5) observed that two embryos of Gigantocypris agassizi Poulsen, 1962, have limbs 1 to 5 or 6 (embryo with shell length of $2.4 \mathrm{~mm}$ had limbs 1 to 5 but no caudal furca, and a larger embryo with shell length of $3.4 \mathrm{~mm}$ had limbs 1 to 6 and a caudal furca). comparisons: The new species, B. beta, differs from $B$. breviata in having no bristles on the ventral margin of the 6th limb, in having fused basis and endopod articles on the maxilla, and in not having a bristle following the claws on each lamella of the furca. Its mandible differs from those of $B$. hazeli and $B$. alpha in having only 1 stout spinous bristle on the basis endite (B. hazeli and B. alpha have 2 stout spinous bristles, and B. breviata has 3 on the adult female and 2 on the A-1 female).

The total number of bristles on appendages of the four known species of Bruuniella are compared in Table 1. Unfortunately, because of the small size of the specimens, the number of bristles on the maxilla and 5th limb are difficult to count when the appendages are on the body, and they often fragment in the process of removal from the body, so the number of bristles on those appendages are mostly approximate. The main differences in appendages are described in the preceding paragraph.

An anterior-to-posterior profile of the total number of bristles on appendages of adult females of the two species of Cylindroleberidinae in the collection from Johnston Atoll 


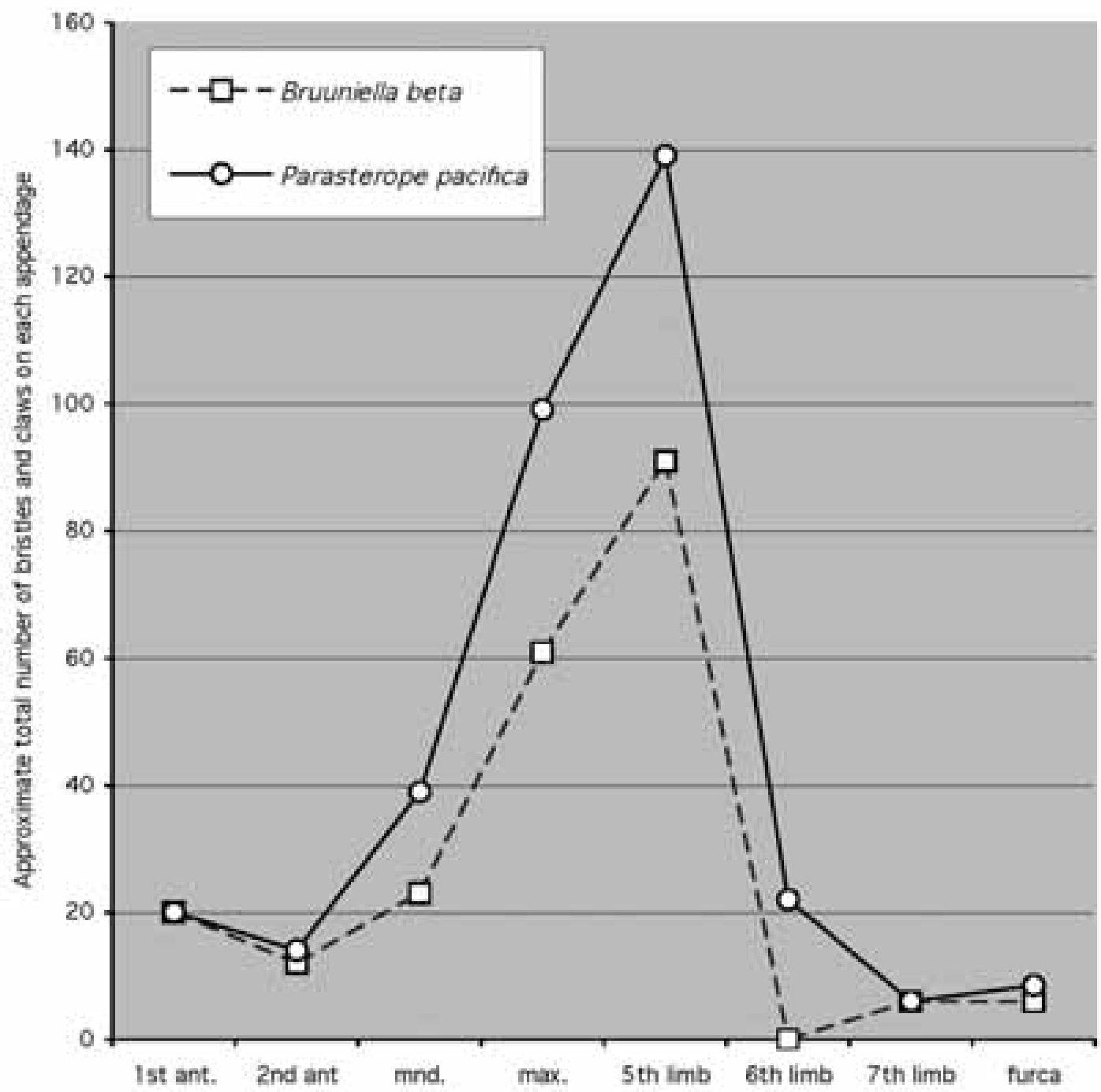

Figure 22. Anterior-to-posterior profile of total number of bristles on appendages of adult females of Bruuniella beta, n. sp., holotype, USNM 1023197, and Parasterope pacifica, n. sp., holotype, UsNm 1023194.

is shown graphically in Figure 22. The adult female of $P$. pacifica bears a larger number of bristles than $B$. beta on the mandible, maxilla, and 5 th and 6 th limbs.

SEXUAL DIMORPHISM OF Bruniella beta: Only major dimorphisms are described.

Carapace: The adult male is shorter than the adult female: length of male $0.73 \mathrm{~mm}$, length of female $0.80-0.89 \mathrm{~mm}$.

First antenna: Dimorphisms are consider- able and more than in other members of the Cylindroleberididae. The 1st antennae of the adult female and male are illustrated in Figure $23 A, B$. Mainly, the ventral sensory bristle is in the usual location on the 5th article on the adult female and juvenile but on the adult male is located proximal to the dorsal bristles of the 3rd article, which are on the margin opposite the base of the sensory bristle. Presumably, the base of the sensory bristle of 


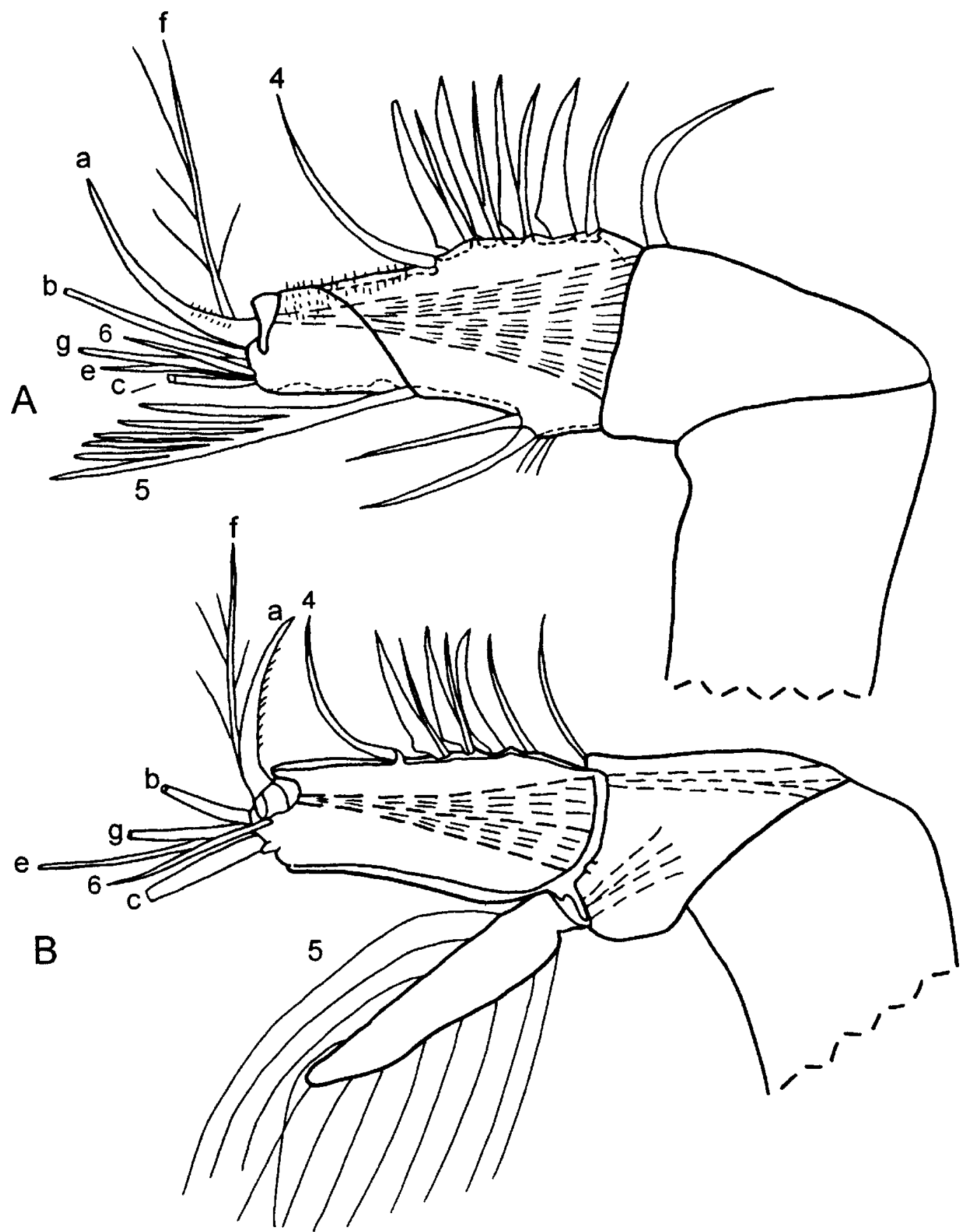

Figure 23. Brunniella beta, n. sp., right 1st antenna, medial view: $A$, adult female, holotype, usNm 1023197; $B$, adult male, paratype, UsNm 1023210 (not all filaments shown on sensory bristle of 5th article). 
the male is on the 5th article, but because sutures separating articles 3 and 4 are absent the bristle appears to be on the 3rd article. Less unusually the male sensory bristle is stouter and bears more numerous filaments. Some minor dimorphisms are present: the 3rd article of the male bears 3 stout dorsal bristles compared with 4 on the female; the 4th article of the male is without 2 ventral bristles present on the female; the 5 th and 6th articles of the male are without the numerous minute spines present on the female; and the a-claw of the 7th article bears slender spines along the concave edge, whereas 2 short rows of minute proximal spines are on the a-claw of the female.

Second antenna: The reflexed endopod of the 2 nd antenna of the adult male is the type usually present on adult male Cylindroleberididae.

Mandible: The sutures separating articles 2 and 3 of the endopod of the adult male are better defined than those of the female, and the combined articles bear 2 claws on the male and 3 on the female.

Fifth limb: No major differences, although the number of small bristles on the surfaces of the combs may differ slightly.

Sixth limb: No apparent dimorphism.

Seventh limb: Adult male with 4 terminal bristles compared with 6 on female.

Furca: Adult male with 5 claws on each lamella, female with 6 , but variability not determined.

Bellonci Organ: Similar in both sexes.

Eyes: Well developed in both sexes.

Gills: Absent in both sexes.

Lips: Similar in both sexes.

Posterior of body: Female with hairs along posterior margin; hairs not present on adult male.

Genitalia: Male with large copulatory organs.

Foreign organisms: Single adult male in collection without the reddish microspheres present within carapaces of most adult females and juveniles.

ontogeny: Only the last three freeliving instars of the species are in the collection. The sex of late instars is determined by the morphology of the endopod of the 2nd antenna. The sex of the A-3 instars in the collection could not be determined, and the A-1 and A-2 instars studied are males. The presence of a ventral bristle on the 4th article of the 1st antenna of the A-3 instar suggests that it is the third instar; if so, the species has five instars (see Hiruta 1983:673). The 1st antenna and mandible of male instars of $B$. beta are of the same type as those appendages on the adult female and differ considerably from those of the adult male. The proximal location of the sensory bristle of the 1st antenna of the adult male is a more extreme change than observed in other members of the Cylindroleberididae. An embryo obtained from within a female marsupium bears appendages 1 to 5 (and possibly the 6th limb) and the caudal furca, all less well developed than those of the 1st free-living instar.

DISCUSSION OF FOREIGN ORGANISMS: The red microspheres within the carapaces of most females and juveniles of $B$. beta were examined by Maria Faust (Smithsonian Institution), who concluded that they are neither algae nor dinoflagellates based partly on their lack of fluorescence; Theodore Bayer (Smithsonian Institution) confirmed that they are not corals. Possibly, the microspheres are inorganic precipitates resulting from bacterial activity within the carapace.

The coiled wormlike organisms within the body of two specimens were examined by Duane Hope (Smithsonian Institution), who concluded that they are not nematodes. L.S.K. has not observed similar organisms in other myodocopids previously studied.

\section{ACKNOWLEDGMENTS}

We thank Ralph DeFelice and S. L. Coles, Bishop Museum, for sending the specimens upon which this paper is based and for correspondence concerning them. The collecting was funded and given logistic support by the U.S. Fish and Wildlife Service. Camera lucida drawings were inked by Megan Bluhm. Molly K. Ryan prepared the map and graph (Figures 1 and 22). We thank Maria Faust, Theodore Bayer, and Duane Hope (all of the 
Smithsonian Institution) for examining foreign organisms present in some specimens of B. beta. We thank Jury A. Rudjakov and Anne C. Cohen for reviewing the manuscript and making many helpful suggestions.

\section{Literature Cited}

Baker, J. H. 1978. Two new species of Parasterope (Myodocopina, Ostracoda) from southern California. Crustaceana (Leiden) 35:139-151.

Brady, G. S. 1898. On new or imperfectly known species of Ostracoda, chiefly from New Zealand. Trans. R. Soc. Edinb. 14:489-525.

Cohen, A. C. 1989. Comparison of myodocopid ostracodes in two zones of the Belize Barrier Reef near Carrie Bow Cay with changes in distribution 1978-1981. Bull. Mar. Sci. 45:316-333.

Cohen, A. C., J. W. Martin, and L. Kornicker. 1998. Homology of Holocene ostracode biramous appendages with those of other crustaceans: The protopod, epipod, exopod and endopod. Lethaia 31:251-265.

Coles, S. L., R. C. DeFelice, and D. Minton. 2001. Marine species survey of Johnston Atoll, Central Pacific Ocean, June 2000. Bishop Mus. Tech. Rep. 19.

Hartmann, G. 1984. Zur Kenntnis der Ostracoden der polynesischen Inseln Huahine (Gesellschaftsinseln) und Rangiroa (Tuamotu-Inseln). Mitt. Hamb. Zool. Mus. Inst. 81:117-169.

Hiruta, S.-I. 1979. A new species of Batbyleberis Kornicker from Hokkaido, with reference to the larval stages (Ostracoda: Myodocopina). J. Fac. Sci., Hokkaido Univ. 22:99-121.

1983. Post-embryonic development of myodocopid Ostracoda. Pages 667-677 in R. F. Maddocks, ed. Applications of Ostracoda. Department of Geosciences, University of Houston, Houston, Texas.

Kajiyama, E. 1912. The Ostracoda of Misaki, part 2. Dobutsugaku Zasshi 24: 609-619.

Kornicker, L. S. 1975. Antarctic Ostracoda
(Myodocopina) parts 1 and 2. Smithson. Contrib. Zool. 163:1-720.

- 1981a. Revision, distribution, ecology, and ontogeny of the ostracode subfamily Cyclasteropinae (Myodocopina: Cylindroleberididae). Smithson. Contrib. Zool. 319:1-548.

. 1981b. Benthic marine Cypridinoidea from Bermuda (Ostracoda). Smithson. Contrib. Zool. 331:1-15.

-1986. Cylindroleberididae of the western North Atlantic and the northern Gulf of Mexico, and zoogeography of the Myodocopina (Ostracoda). Smithson. Contrib. Zool. 425:1-139.

- 1991. Myodocopid Ostracoda of Enewetak and Bikini Atolls. Smithson. Contrib. Zool. 505:1-140.

Kornicker, L. S., and F. E. Caraion. 1974. West African myodocopid Ostracoda (Cylindroleberididae). Smithson. Contrib. Zool. 179:1-78.

Kornicker, L. S., and T. M. Iliffe. 2000. Myodocopid Ostracoda from Exuma Sound, Bahamas, and from marine caves and blue holes in the Bahamas, Bermuda, and Mexico. Smithson. Contrib. Zool. 606:1-98.

Müller, G. W. 1906. Ostracoda. In Carl Chun, ed. Wissenschaftliche Ergnebnisse der Deutsche Tiefsee-Expedition ... 1898-1899, 8 (2): 1-154 + pls. 1-31. G. Fischer, Jena, Germany.

Poulsen, E. 1962. Ostracoda-Myodocopa, 1: Cypridiniformes-Cypridinidae. Dana-Rep. Carlsberg Found. 57:1-414.

- 1965. Ostracoda-Myodocopa, 2: Cypridiniformes-Rutidermatidae, Sarsiellidae and Asteropidae. Dana-Rep. Carlsberg Found. 65:1-484.

Sars, G. O. 1865 [1866]. Oversigt AF Norge marine Ostracoder. Forhandlinger i Videnskabs-Selskabet I Christiania 8:1130.

Skogsberg, T. 1920. Studies on Marine Ostracods I: Cypridinids, halocyprids, and polycopids. Zool. Bidr. Upps., supplement $1: 1-784$.

Tseng, W.-Y. 1975. Biology of the pelagic ostracod Euconchoecia elongata Müller. Lab. Fish. Biol. Rep. (Taiwan) 27:1-183. 


\section{Appendix}

Station Data

(For More Comprehensive Station Data, See Coles et al. [2001:7-10])

Station 3: 16 June $2000,16^{\circ} 45^{\prime} 53.3^{\prime \prime} \mathrm{N}, 169^{\circ} 31^{\prime} 2.4^{\prime \prime}$

$\mathrm{W}$, depth $2-3.5 \mathrm{~m}$. Located in lagoon north of Akau (North) Island. Substrate almost completely covered with tabular coral, and with small amount of sand beneath corals.

Parasterope pacifica: 7 specimens.

Station 4: 17 June 2000, $16^{\circ} 47^{\prime} 10.0^{\prime \prime} \mathrm{N}, 169^{\circ} 27^{\prime} 58^{\prime \prime}$ W, depth 8.5-31.5 m. Donovan's Reef, ca. $8 \mathrm{~km}$ northeast of Johnston Island; station is seaward of the reef, which is about $1 \mathrm{~km}$ east of main Johnston Atoll reef. Slope of reef at station gradually goes from depth of 8.5 to $21 \mathrm{~m}$, then is vertical to $31.5 \mathrm{~m}$. Substrate of consolidated limestone, moderate coral cover, coarse sand at base of reef.

Bruuniella beta: 3 specimens (1 female with embryos in carapace).

Station 5: 18 June 2000, $16^{\circ} 44^{\prime} 52.3^{\prime \prime} \mathrm{N}, 169^{\circ} 31^{\prime} 3.5^{\prime \prime}$ $\mathrm{W}$, depth $2-9.5 \mathrm{~m}$. Station located near range finder marking main channel through lagoon. Substrate of range finder pilings, coral, and coarse sand in channels.

Bruuniella beta: 26 specimens.

Station 6: 18 June 2000, $16^{\circ} 44^{\prime} 51.6^{\prime \prime}$ N, $169^{\circ} 30^{\prime} 28.9^{\prime \prime}$ $W$, depth $1.5 \mathrm{~m}$. Shallow area northeast of Sand Island. Substrate of sparse coral cover on flat limestone bottom.

Parasterope pacifica: 5 specimens.
Station 7: 18 June 2000, $16^{\circ} 44^{\prime} 18.0^{\prime \prime} \mathrm{N}, 169^{\circ} 31^{\prime} 0^{\prime \prime} \mathrm{W}$, depth $0.5-9 \mathrm{~m}$. Station along eastern side of dredged channel east of Johnston Island and adjacent to shallow reef area. Substrate of linear reefs divided by narrow sand channels.

Bruuniella beta: 4 specimens.

Station 8: 19 June 2000, $16^{\circ} 46^{\prime} 47.2^{\prime \prime} \mathrm{N}, 169^{\circ} 29^{\prime} 28.7^{\prime \prime}$ $\mathrm{W}$, depth 3-20 m. Outer reef slope, station in break between main reef and a smaller reef to northeast on outer reef slope. Substrate of live and dead coral and consolidated limestone.

Bruuniella beta: 3 specimens.

Station 9: 19 June 2000, $16^{\circ} 45^{\prime} 29.5^{\prime \prime} \mathrm{N}, 169^{\circ} 31^{\prime} 29.3^{\prime \prime}$ W, depth 1-5 m. Cucumber Flats in lagoon seaward of Johnston Island near inner reef edge. Substrate of extensive sand patches among reefs.

Bruuniella beta: 1 specimen.

Station 10: 20 June 2000, $16^{\circ} 42^{\prime} 43.7^{\prime \prime} \mathrm{N}, 169^{\circ} 31^{\prime} 2.4^{\prime \prime}$ $\mathrm{W}$, depth 2-9.5 m. South Channel, at east edge of channel dredged in 1963-1964 for fill material. Substrate of rubble cobbles near coral reef and coarse sand in channel. Southernmost station sampled.

Bruuniella beta: 11 specimens.

Station 11: 20 June 2000, $16^{\circ} 43^{\prime} 18.0^{\prime \prime} \mathrm{N}, 169^{\circ} 31^{\prime} 58^{\prime \prime}$ $\mathrm{W}$, depth 3-10 m. Station along sewage discharge pipe from treatment plant on south jetty of Johnston Island to discharge point about $500 \mathrm{~m}$ south of jetty. Substrate of sand patches and reef covered with algae.

Bruuniella beta: 6 specimens (1 adult male; 1 ovigerous female with embryos inside shell).

Parasterope pacifica: 4 specimens. 